Redox-Related Mechanisms to Rebalance Cancer-Deregulated Cell Growth Peer-reviewed author version

STEVENS, An-Sofie; PIROTTE, Nicky; WOUTERS, Annelies; VAN ROTEN, Andromeda; VAN BELLEGHEM, Frank; WILLEMS, Maxime; CUYPERS, Ann; ARTOIS, Tom \& SMEETS, Karen (2016) Redox-Related Mechanisms to Rebalance Cancer-Deregulated Cell Growth. In: CURRENT DRUG TARGETS, 17(12), p. 1414-1437.

DOI: $10.2174 / 1389450116666150506112817$

Handle: http://hdl.handle.net/1942/22847 


\section{Redox-related mechanisms to rebalance cancer-deregulated cell growth}

2

3

\section{The anticarcinogenic mechanisms of regeneration}

\section{An-Sofie Stevens ${ }^{1}$, Nicky Pirotte ${ }^{1}$, Annelies Wouters ${ }^{1}$, Andromeda Van Roten ${ }^{1}$, Frank Van Belleghem ${ }^{1,2}$,}

Maxime Willems ${ }^{3,4}$, Ann Cuypers ${ }^{1}$, Tom Artois ${ }^{1}$, Karen Smeets ${ }^{1,}$

${ }^{1}$ Centre for Environmental Sciences, Hasselt University, Agoralaan, building D, BE 3590, Diepenbeek, Belgium.

${ }^{2}$ Faculty of Management, Science and Technology, Open University, Valkenburgweg 177, Heerlen, The Netherlands.

${ }^{3}$ Laboratory of Pharmaceutical Technology, Faculty of Pharmaceutical Sciences, Ghent University, 9000 Ghent, Belgium.

${ }^{4}$ Laboratory of Environmental Toxicology and Aquatic Ecology, Ghent University, Jozef Plateaustraat 22, 9000 Ghent, Belgium.

\section{*Address correspondence to:}

Karen Smeets. Zoology: Biodiversity and Toxicology, Centre for Environmental Sciences, Hasselt University, Agoralaan, building D, BE 3590 Diepenbeek, Belgium. e-mail: karen.smeets@uhasselt.be; telephone: $+3211268319$

An-Sofie Stevens and Nicky Pirotte have contributed equally to this work and should be considered co-first authors.

\section{西}

(1)


A delicate balance exists between the process of carcinogenesis and tissue regeneration. A number of malignant tumours are considered the outcome of an impaired or incomplete regeneration process, resulting in persistently dividing cells. Regeneration-competent tissues and animals are able to prevent and counteract growth abnormalities and seem to have a low vulnerability to chemical carcinogenesis. Cancer cell survival depends, among other things, on various redox-related mechanisms, which are targets of currently developed therapies. Disadvantages of these therapies are a lack of specificity and drug resistance. As the majority of these redoxrelated mechanisms also play an important role in successful and coordinated cell functioning and reproduction, the regeneration process offers a unique parallel context for modern cancer research. This review focuses on the interconnections between regeneration and carcinogenesis and how an understanding of regenerative forces and redox-controlled mechanisms could contribute to the identification of new therapeutic targets to block the growth and survival of cancer cells. 


\section{Reactive oxygen species}

70

71

\subsection{Different types of reactive oxygen species}

Reactive oxygen species or ROS are reactive molecules that originate from oxygen as by-products of aerobic metabolism or through enzymatic production [1-4] (Fig. 1). Oxygen $\left(\mathrm{O}_{2}\right)$ in its ground state contains two unpaired electrons with parallel spins (triplet oxygen) and is not that reactive. The excited state of molecular oxygen is singlet oxygen, which is formed via photo-excitation. Singlet oxygen has two electrons with antiparallel spins and forms covalent bonds with other molecules more easily [4,5]. The superoxide anion radical $\left({ }^{\circ} \mathrm{O}_{2}^{-}\right)$is formed after a one-electron reduction of oxygen $[3,6]$. This radical functions both as a reductant as well as an oxidant, is shortlived and is not likely to diffuse across the cell membranes, which makes its effects rather localized [6]. When superoxide receives a proton the more reactive hydroperoxyl radical $\left({ }^{\circ} \mathrm{HO}_{2}\right)$ is generated. The two-electron reduction product of oxygen is hydrogen peroxide $\left(\mathrm{H}_{2} \mathrm{O}_{2}\right)$, one of the most stable ROS. Given that it easily crosses membranes, an important signalling function is attributed to this molecule [6]. The Haber-Weiss reaction involves the so-called Fenton reaction in which hydrogen peroxide reacts with ferrous ions $\left(\mathrm{Fe}^{2+}\right)$, yielding ferric ions $\left(\mathrm{Fe}^{3+}\right)$, a hydroxyl radical $\left({ }^{\circ} \mathrm{OH}\right)$ and a hydroxide anion $\left(\mathrm{OH}^{-}\right)$. The nitric oxide radical $\left({ }^{\circ} \mathrm{NO}\right)$ plays an important role in signal transduction and metabolism of nitric oxide gives rise to a series of compounds called reactive nitrogen species (RNS) [1, 3]. Nitric oxide is formed in higher organisms through the oxidation of a terminal guanidonitrogen atom of L-arginine, which is mostly catalysed by the enzyme nitric oxide synthase (NOS) [3]. When the superoxide anion reacts with nitric oxide, the highly reactive peroxynitrite $\left(\mathrm{ONOO}^{-}\right)$is formed [6]. Other RNS include the nitrosonium cation $\left(\mathrm{NO}^{+}\right)$and the nitroxyl anion $\left(\mathrm{NO}^{-}\right)$[3].

\subsection{Physiological sources of ROS production}

Although most ROS are produced as by-products of metabolic and enzymatic activities, aerobic organisms also utilize and actively produce ROS for numerous important physiological processes [6, 7]. Oxidoreductases catalyze the electron transfer from the reductant (electron donor) to the oxidant (electron acceptor) in aerobic conditions leading to the production of ROS. Multiple oxidoreductases are localised in different cellular compartments and have been identified so far as potential ROS sources, including cyclooxygenase (luminal side of endoplasmic reticulum and nuclear membrane), lipoxygenase (cytosol, nucleus), cytochrome P450 enzymes (endoplasmic reticulum, mitochondria), nitric oxide synthase (different subcellular compartments, including the sarcoplasmic reticulum, mitochondria and peroxisome), xanthine oxidase (cytosol, mitochondrial matrix, peroxisome), mitochondrial NADH/ubiquinone oxidoreductase (complex I) and NADPH oxidase (NOX, cell membrane) [8]. Despite the diversity of all these ROS-producing enzymes, the majority of cellular ROS is produced by the mitochondrial respiratory complexes and the NADPH oxidases. 


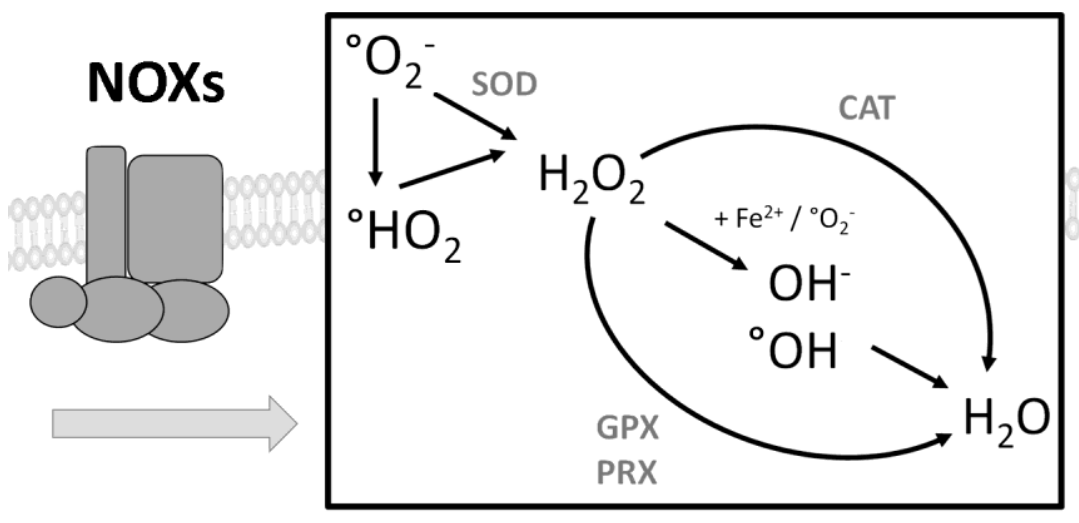

Mitochondria

103 Figure 1: Production of reactive oxygen species. The two main physiological sources of ROS production are the transmembrane NAPDH oxidase (NOX) enzymes and the mitochondrial complexes I and III. A simplified overview of the different ROS species and the involved enzymes is presented. Superoxide anions $\left({ }^{\circ} \mathrm{O}_{2}^{-}\right)$give rise to hydroperoxyl radicals $\left({ }^{\circ} \mathrm{HO}_{2}\right)$ or hydrogen peroxide $\left(\mathrm{H}_{2} \mathrm{O}_{2}\right)$, through superoxide dismutase (SOD) activity. The reaction of hydrogen peroxide $\left(\mathrm{H}_{2} \mathrm{O}_{2}\right)$ with $\mathrm{Fe}^{2+}$ in the Fenton reaction leads to the formation of the hydroxyl radical $\left({ }^{\circ} \mathrm{OH}\right)$ and hydroxide anion $\left(\mathrm{OH}^{-}\right)$, which can eventually be converted to molecular water $\left(\mathrm{H}_{2} \mathrm{O}\right)$. Enzymatic activity of catalase (CAT), glutathione peroxidase (GPX) and peroxiredoxin (PRX) also convert $\mathrm{H}_{2} \mathrm{O}_{2}$ to molecular water.

\subsubsection{Mitochondrial respiratory complexes}

Under normal physiological conditions, most of the ROS present in cells (discussed in section 1.1) are produced indirectly as by-products of the mitochondrial respiratory chain. Oxygen acts as the final acceptor of the electrons transferred in the mitochondrial chain, in the end undergoing a four-electron reduction to form water. The generation of the superoxide anion, via electron leakage, occurs primarily at complex I (NADH/ubiquinone oxidoreductase) and complex III (ubiquinol/cytochrome c oxidoreductase) of the mitochondrial chain, depending on the metabolic state of the mitochondria $[9,10]$. When both respiration and ATP production are low, the production of superoxide anions is high and the reverse electron transfer (RET) and FMN (flavin mononucleotide, located in complex I) are the primary sources of superoxide anion production. When respiration and ATP production are high, the production of superoxide anions is considerably lowered [10]. Approximately $0.12-2 \%$ of the respiratory oxygen results in the superoxide anion in vitro, as measured in isolated mitochondria. However, the actual in vivo values of mitochondrial ROS production are most likely considerably lower, probably because the isolated mitochondria are maintained in high non-physiological concentrations of oxygen [2]. The produced superoxide anions are converted into hydrogen peroxide by manganese superoxide dismutase (MnSOD), the only isoform of superoxide dismutase present in the mitochondrial matrix [10]. In contrast to the superoxide anions, hydrogen peroxide is able to penetrate the mitochondrial membranes, thereby affecting cell signalling events.

\subsection{2. $\quad$ NADPH oxidases}


NADPH oxidases or NOX enzymes distinguish themselves from other oxidoreductases, including the mitochondrial complexes, in that they produce ROS as an end product instead of creating them as by-products of their catalytic pathways. So far, five human NOX isoforms (NOX 1-5) have been identified as well as two dual oxidases (DUOX 1 and 2). All NOXs are comprised of membrane-bound subunits and they all differ from one another in terms of tissue distribution, domain structure, subunit requirements and mechanisms of activation. The catalytic subunit of all NOX isoforms consists of a C-terminal dehydrogenase domain with an NADPH binding site together with a bound flavin adenine dinucleotide (FAD). When the NOX enzymes are activated and their subunits have assembled, the electrons of NADPH are first transferred to FAD and subsequently to the two haem groups bound to the $\mathrm{N}$-terminal domain, which finally passes them to two molecular oxygen molecules across the membrane forming superoxide anions [6]. NOX-derived superoxide is generated in the extracellular environment and dismutated quickly (catalysed by CuZnSOD) to hydrogen peroxide. Hydrogen peroxide diffuses freely across cell membranes, most likely facilitated by the presence of aquaporin channels [11].

Genes encoding NOX subunits are found in animals as well as plants, but not in prokaryotic organisms. Their early evolutionary appearance and conservation in both lower and higher eukaryotes as well as their wide distribution in various cell types (especially in mammals) are indicative of the fundamental roles that NOXs probably play in cell functioning. Several studies have shown their importance in the modulation of redox-sensitive, intracellular signalling pathways, including the activation of certain transcription factors (e.g. AP-1 and NF-kB) [8], as well as in physiological processes such as immune responses and development. In order to control the redox balance, cells possess various direct and indirect antioxidant mechanisms to regulate the ROS levels.

\subsection{Redox regulation and signalling}

Despite their positive signalling function, too much ROS can induce irreversible oxidative damage to macromolecules such as nucleic acids, lipids and proteins, resulting in the loss of cellular function or cell death. This redox-induced damage has been linked to the progression of numerous pathologies such as cardiovascular diseases, inflammation, neurological malfunctioning and cancer [12]. In order to maintain homeostasis, the ROS metabolism is tightly regulated by a variety of redox mechanisms that control the redox (oxidant/antioxidant) balance [13].

The antioxidative system is composed of nonenzymatic and enzymatic antioxidants. Nonenzymatic antioxidants are classified as metabolic antioxidants (e.g., glutathione, L-arginine, metallothioneins and ferritins) and dietary antioxidants (e.g. tocopherol, ascorbate and $\beta$-carotene) [14]. Some act as chain-breaking antioxidants (by intercepting the chain-carrying radicals), thereby slowing down or stopping oxidative chain reactions (e.g. tocopherol intercepts peroxyl radicals). Others act as preventive antioxidants by intercepting oxidizing species before damage occurs (e.g. $\beta$-carotene quenches singlet oxygen or metallothionein chelates toxic elements such as $\mathrm{Cd}, \mathrm{As}, \mathrm{Hg}$, etc.) [13]. Enzymatic antioxidants are considered preventive as they catalyse neutralization of ROS by elimination [15]. The enzyme superoxide dismutase (SOD) catalyses the dismutation of superoxide into oxygen and hydrogen peroxide. In human cells, there are three isoforms of SOD differing in their subcellular location and metallic cofactor, i.e. cytosolic CuZnSOD (SOD1), mitochondrial MnSOD (SOD2) and extracellular CuZnSOD (SOD3). The enzyme catalase (CAT) decomposes hydrogen peroxide to oxygen and water. Glutathione 
to alcohols and water, thereby oxidizing the antioxidant metabolite glutathione (GSH). The oxidized glutathione cofactor (GS-SG; glutathione disulphide) is then reduced back to its original state (2 GSH) by glutathione reductase (GR). Peroxiredoxins (PRX) catalyse the reduction of hydrogen peroxide as well as organic hydroperoxides such as cytokine-induced peroxide. Thioredoxins (TRXs), localized in the cytoplasm and mitochondria, consist of multiple isoforms allowing the reduction of oxidized proteins by cysteine thiol-disulfide exchange [15]. All these nonenzymatic and enzymatic antioxidant systems maintain a controlled redox balance and protect the cells against oxidative stress.

The enzymatic antioxidant defence system is tightly regulated by various redox-controlled transcription factors, such as the nuclear factor erythroid-2-related factor 2 (Nrf2), the endonuclease 1/redox effector factor 1 (APE1/Ref-1), the family of forkhead box type $\mathrm{O}$ (FoxO), the ataxia-telangiectasia mutated (ATM) protein kinase and the nuclear factor kappa-light-chain-enhancer of activated B cells (NF-kB). Nrf2 activates the transcription of several antioxidant enzymes such as SOD1, CAT, GPX2, GR and TRX via the antioxidant responsive element (ARE). In physiological conditions, Nrf2 is retained in the cytoplasm by anchoring to the Kelch-like ECHassociated protein 1 (Keap1). Internal or external induced elevation of ROS levels oxidize the reactive thiol groups of Keap1 causing the dissociation of Nrf2. The activated Nrf2 translocates into the nucleus and forms a heterodimer with small Maf proteins to activate genes in the oxidative stress response [4, 16-18]. APE1/Ref-1 plays a pivotal role in the DNA base excision repair pathway and controls the intracellular redox state in two ways: by inhibiting Rac-1 regulated NOX and by reducing oxidized transcription factors such as hypoxia-inducible factor $1 \alpha$ (HIF$1 \alpha)$, Nrf2, and the tumour suppressor protein p53 $[19,20]$. The latter transcription factor p53 is an essential component in the regulation of cell cycle arrest, cellular senescence and apoptosis and also plays an antioxidant role in the response to oxidative stress [1,21]. FoxO transcription factors control intracellular ROS levels by upregulating the antioxidative enzymes CAT and SOD2 [22]. ATM protein kinase, a regulator of the cellular response to DNA double-stranded breaks (DSBs), controls the intracellular levels of ROS, among others, by stimulating NADPH synthesis leading to suppression of protein synthesis and activation of autophagy [23-25]. $\mathrm{NF}-\mathrm{kB}$, a transcription factor playing a crucial role in cell survival, is activated by oxidative stress and in turn activates genes coding for ferritin (FT) and SOD2 [26].

ROS not only activate the antioxidant defence system, they also regulate important processes such as cell proliferation, differentiation and survival through oxidation of redox-sensitive protein kinases and protein phosphatases, mainly at the cysteine residue. The cysteine sulfhydryl group undergoes different degrees of oxidations resulting in the generation of sulphenic acid $(-\mathrm{SOH})$, sulphinic acid $\left(-\mathrm{SO}_{2} \mathrm{H}\right)$ or sulphonic acid $\left(-\mathrm{SO}_{3} \mathrm{H}\right)$. Cysteine oxidation either leads to inhibition or activation of the downstream proteins [27, 28]. An example of such an indirect regulation of transcription factors is the redox-controlled stimulation of MAP kinases (MAPKs). Three MAPK enzymes have been identified: extracellular signal-regulated kinase (ERK), C-Jun N-terminal kinase (JNK) and p38 kinase [29-31]. Their actions alter the expression of multiple genes involved in cell proliferation, differentiation and apoptosis, including, among others, $c y c l i n D 1$ and $c d k 2$. ROS-induced stimulation of MAPKs occurs via the inhibition of 1) a negative MAPK regulator MKP, 2) thioredoxin (TRX), 3) a negative regulator of the apoptosis signal-regulating kinase (ASK1), or via the activation of 1) a proto-oncogene, 2) a non-receptor tyrosine kinase (SRC), 3) a positive regulator of MAPKs. Other pathways that are activated in response to an altered redox state are the phosphoinositide 3-kinase (PI3K)/Akt pathway, the NF-אB system, p53 activation, and 
the heat shock response. In general, the heat shock response, ERK, PI3K/Akt and NF-kB signalling pathways are involved in the prosurvival response of the cell, whereas activation of p53, JNK and p38 are linked to apoptosis [2]. The balance between prosurvival and apoptotic responses strongly depends on the intensity and frequency of the oxidative stimulus [4].

\section{4. $\quad$ ROS-(de)regulated processes}

ROS are important in numerous physiological processes including immunology, wound healing and angiogenesis. However, an imbalance between the production and detoxification of ROS has been linked with ageing and with a broad range of diseases such as cancer, insulin resistance, diabetes mellitus, cardiovascular diseases, atherosclerosis and neurodegenerative conditions [32]. Here, we will focus on redox-related processes within the framework of potential anticarcinogenic targets, the scope of this review.

\subsubsection{Cellular responses}

ROS \& cell death

ROS affect the process of cell death in both a direct and indirect manner. Due to their chemically reactive state, ROS molecules interact directly with various cellular components, including the nucleotides of DNA. These interactions can cause single- and double-stranded DNA breaks, purine, pyrimidine or deoxyribose modifications and DNA cross-links, leading to mutations [4, 33, 34]. The main ROS that cause DNA damage are the hydroxyl radical $\left({ }^{\circ} \mathrm{OH}\right)$, singlet oxygen $\left({ }^{1} \mathrm{O}_{2}\right)$ and one-electron oxidants [35]. Dependent on the severity of the damage and the ability of the cell to adapt to or resist the stress and repair the cellular damage, different responses are possible. Moderate damage activates the repair machinery whereafter cell proliferation continues. However, when the DNA damage is irreparable, cell death is initiated $[2,36]$. ROS-induced cell death involves both necrosis and apoptosis, depending on the severity of the insult. An important feature in preventing cell death is autophagy, which is activated by ROS and once activated reduces oxidative stress by degrading proteins and damaged mitochondria (mitophagy), a primary source of intracellular ROS [37, 38]. Some DNA regions are more susceptible to ROSinduced damage, especially regions rich in guanine bases since different ROS, including singlet oxygen and hydroxyl radicals, convert guanine to 8-oxo-7,8 dihydroguanine resulting in single base DNA damage. Due to their high guanine content, telomeres - the protective and repetitive TTAGGG sequence at the end of the chromosomes - are highly sensitive to ROS. Moreover, in contrast to the majority of the genomic DNA, the repair system of the telomeric region is inefficient in repairing single-stranded breaks. Accelerated degradation of these protective sequences eventually results in destruction of the DNA at the end of the chromosome [39, 40]. Interestingly, overexpression of the telomerase reverse transcriptase (TERT), the catalytic subunit of the telomerase enzyme that elongates the telomeres and is linked with immortalization and stem cell populations, reduces intracellular ROS levels and cell death [41, 42].

Besides inducing cell death through DNA damage, ROS also act as upstream signalling molecules in the induction of apoptosis [36]. Chen and colleagues showed that ROS production results in apoptosis of neuronal cells in a concentration- and time-dependent manner through activation of the MAPK pathways [43]. In some cells, a positive feedback loop via p53 helps to reach critical ROS levels that induce a successful apoptotic response [2]. Moreover, the expression of antiapoptotic factors, such as Bcl-2 and Bcl-x, is also associated with protection 
against ROS. During tumour necrosis factor (TNF- $\alpha$ )-induced apoptosis, Bcl-2 prevents the accumulation of ROS and thus the subsequent apoptotic events (mitochondrial membrane depolarization, Bax relocalization, cytochrome $\mathrm{c}$ release, caspase activation and nuclear fragmentation). Similarly, Bax and Bcl-x are able to respectively increase or decrease GSH levels, without interfering with other antioxidant enzymes such as SOD, CAT, and GPX/GR [9].

248 The most important MAPK group via which ROS induce cell proliferation is the ERK family. This MAPK pathway is a known intracellular checkpoint of mitosis. Inhibiting or stimulating the ERK signalling results in either an inhibition or enhancement of cell proliferation [29]. In this process, JNK acts as a final mediator of ERK to stimulate cell proliferation. Cross-talk between the different MAPK cascades ultimately controls the balance between proliferation, differentiation or apoptosis [29]. Considering their function, it is not surprising that ERK, JNK and p38 MAPK signalling pathways are all associated with tumourigenesis. For example, in various cancer types in both humans and mice, ERK1 and ERK2 are upregulated while JNK and p38 MAPK pathways are often downregulated [31]. Another downstream mechanism through which ROS induce proliferation is the TRX/Ref-1 complex. Thioredoxins (TRXs) are small proteins containing a redox-active disulphide site, while Ref-1 is a multifunctional protein with endonuclease and oxidoreductase activity. TRX reduces the oxidized Ref-1, which in turn reduces the DNA-binding domain of various proliferation-inducing transcription factors, thereby enhancing their activity [7].

\section{ROS \& patterning}

Wnt proteins are essential for normal development. They not only regulate pathways controlling cellular processes such as proliferation and differentiation, but also direct proper pattern formation. The canonical Wnt pathway acts through $\beta$-catenin, which, upon accumulation in the cytoplasm, translocates to the nucleus and associates with different transcription factors, hereby activating the expression of downstream target genes. In the absence of the Wnt ligand, cytoplasmic $\beta$-catenin is degraded and the downstream transcription is inhibited. ROS, including hydrogen peroxide, oxidize nucleoredoxin (NRX) which, in this oxidized state, inhibits the degradation of cytoplasmic $\beta$-catenin. This results in the accumulation of $\beta$-catenin levels and the activation of downstream transcription factors in the absence of the Wnt ligand [7, 36, 44-46]. The importance of ROS in Wnt/ $\beta$-catenin signalling pathway was also demonstrated in in vivo experiments on larvae of Xenopus by Funato and co-workers. They showed that overexpression of NRX inhibits the expression of early targets of Wnt-signalling whereas NRX knockdown resulted in Wnt pathway activation with reduced expression of anterior markers and structures (e.g. absence of eye development) [44]. In intestinal and colon epithelial cells, NOX1-generated ROS play an essential role in the inactivation of NRX [46]. Moreover, a redox-dependent regulation of the Wnt pathway via NRX was also observed in F9 teratocarcinoma cell lines [47, 48].

Stem cells are characterized by their abilities to self-renew and to produce numerous differentiated progeny cells [49]. The fate of stem cells is (co-)directed by the intra- and extracellular (stem cell niche) redox balance: low ROS levels support stem cell maintenance and quiescence while slightly "higher" ROS levels induce stem cell proliferation and eventually differentiation [1, 42, 50, 51]. A rise in ROS levels can induce apoptosis to prevent 
the accumulation of damaged stem cells, as discussed previously [52]. On the other hand, if increased ROS levels can be controlled, stem cell survival is achieved. This redox (re-)balancing is acquired either directly through the activation of antioxidative systems or indirectly via signalling regulators such as PTEN, ATM, HIF, FoxO and Nrf2. Tumour suppressor gene families, such as p53 and p38, are key mediators of ROS-regulated stem cell renewal [51]. In planarians, which have an extensive population of pluripotent stem cells, expression of the tumour suppressor gene p53 is largely restricted to the newly formed progeny of the stem cells and knocking down this gene results in an increase in stem cell number and proliferation causing a depletion of the stem cell population $[49,51,53,54]$.

Since a precise control of the redox balance is crucial for normal cellular functioning, it is not surprising that any unwanted fluctuations in ROS levels can have devastating outcomes, including the formation of cancer. As ROS are involved in both normal physiological processes as well as in diseases, we will focus on this dual role by emphasizing their importance in two related processes: the physiological process of regeneration and the pathologic process cancer. The role of ROS in both the processes will be discussed in the following sections.

\section{ROS modulate carcinogenesis}

\subsection{ROS as a core component of carcinogenesis}

Carcinogenesis is characterized by uncontrolled cell divisions, ultimately resulting in a malignant tumour which invades tissues and metastasizes [55]. Classically, carcinogenesis consists of three stages: initiation, promotion and progression [56].

DNA damaging effects of ROS are mainly involved in the initiation and progression stage (Fig. 2). Both exogenous carcinogens as well as endogenic processes such as chronic inflammation increase oxidative stress and lead to initiated cells [34]. The carcinogenic metal cadmium, for example, induces multiple cancers by increasing internal oxidative damage [52]. It disturbs the redox balance via various mechanisms including the inhibition of antioxidant enzymes (e.g. SOD), the depletion of ROS scavengers (e.g. GSH), the interference with the electron transport chain causing superoxide anion production and the displacement of redox-active metals (e.g. Fe) leading to more hydroxyl radicals. The hydroxyl radical $\left({ }^{\circ} \mathrm{OH}\right)$ induces 8 -hydroxydeoxy guanosine (8-OHdG), one of the major products of DNA oxidation. 8-hydroxydeoxy guanosine levels are elevated in various human cancers and animal tumour models $[33,57,58]$. 8-OHdG not only pairs with cytosine but also with adenine residues, leading to a G:C to T:A transversion, a mutation commonly found in proto-oncogenes, oncogenes and tumour suppressor genes $[33,35,57]$. 


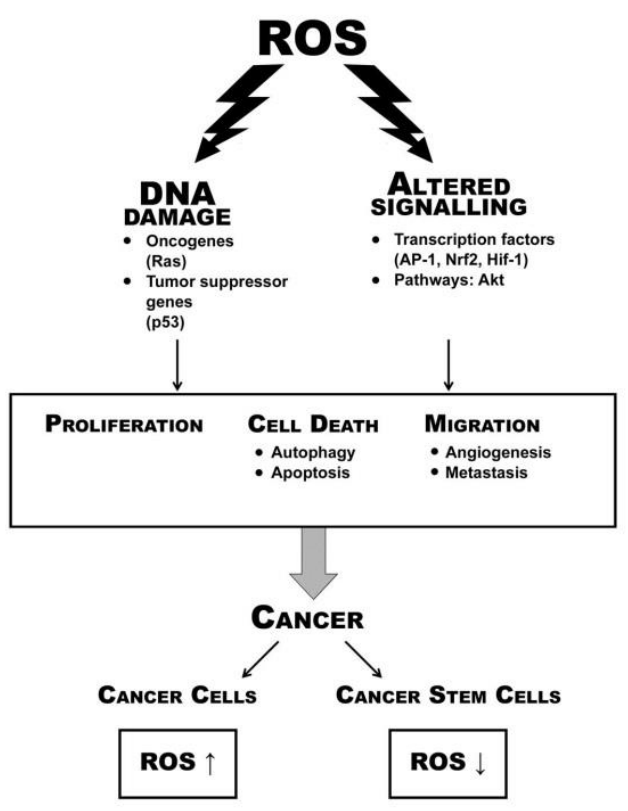

312 Figure 2. Schematic overview of the roles of reactive oxygen species (ROS) in cancer. ROS modulate the carcinogenic process by inducing DNA damage (e.g. in oncogenes such as ras) and by altering signalling pathways (e.g. via the regulation of transcription factors). In this way, ROS initiate and promote cancer through disturbing cell proliferation, death and migration. The amount of ROS necessary to drive carcinogenesis depends on the specific tumour cell type: while cancer cells have elevated ROS levels to accelerate DNA damage, cancer stem cells have lower intracellular ROS levels to facilitate the continuation of the tumour.

Proto-oncogenes mostly code for signal transduction components that promote proliferation, such as growth factors and receptors or transcription factors and, once mutated to an overactive oncogene, they induce uncontrolled proliferation. The ras oncogene - one of the first oncogenes identified - transfers extracellular signals to downstream signalling cascades such as MAPK pathways, eventually stimulating mitogenic processes. Normally, Ras activation has an intrinsic negative feedback loop to ensure a transient transmission of the signal but mutations in ras eliminate this regulating mechanism, leading to uncontrolled mitogenic activation [56, 59]. These mutations are for example found in around 50\% of colon cancers and up to 90\% of pancreatic cancers [59]. Tumour suppressor genes, on the other hand, regulate cell death programs such as apoptosis and, once downregulated or disturbed through mutations, support cell death resistance. The best-known tumour suppressor is undoubtedly p53, which functions in cell cycle arrest, DNA repair, senescence and apoptosis, and is one of the most frequently altered genes in cancer [60-63].

Apart from DNA damage, ROS also modulate the carcinogenic process via transcriptional and signalling alterations which underlie multiple mechanisms of cancer including the clonal expansion of initiated cells during the promotion phase. Commonly targeted transcription factors during carcinogenesis are AP-1, Nrf2 and HIF-1. AP-1 is activated via MAPK and JNK signalling pathways, induces growth and proliferation and reduces oxidized Nrf2 and HIF-1 $\alpha$ [33]. Nrf2 activates numerous stress-related genes and antioxidant enzymes in the presence of oxidative stress. This activation has been linked with aggressive behaviour of different types of cancer, such as 
breast cancer, lung cancer, neuroblastoma and ovarian cancer [33, 64]. The activation of HIF-1 is triggered by a reduced cellular oxygen content, which is often present in tumours as a consequence of their active metabolism and continuous proliferation. Mitochondria function as $\mathrm{O}_{2}$ sensors and signal hypoxia by releasing ROS to the cytosol, which in turn stabilize HIF-1. HIF-1 has more than 60 target genes, all of which promote carcinogenesis via various mechanisms such as cell survival, angiogenesis, invasion and metabolic reprogramming. Elevated HIF1 expression has been linked to poor outcome in various cancer types such as breast cancer [65], cervical cancer [66] or pancreatic tumours [67]. Besides transcription factors, tyrosine kinases/phosphatases such as the kinase Akt, which mediates cell survival via inhibiting proapoptotic transcription factors, are targets of ROS [68].

During the final steps of carcinogenesis, the progression stage, both the DNA damage and signalling defects caused by the disturbed redox balance are important. In this way, ROS induce uncontrolled divisions and additional mutations that drive the tumour towards a malignant neoplasm [33].

\subsection{ROS support the hallmarks of cancer}

347 Throughout the three phases of carcinogenesis, necessary "capabilities" for tumour growth and metastasis are acquired, which are defined as "The hallmarks of cancer" by Hanahan and Weinberg [56]. ROS play a role in each of these capabilities via mutagenic effects, alterations of signalling pathways, effects on the microenvironment and on invasiveness (reviewed in [69] and [70]).

One of the most fundamental hallmarks of cancer is the ability to sustain proliferative signalling. Where normal tissues meticulously regulate the amount of growth-enhancing signals to maintain homeostasis, cancer cells abuse this system by continuously activating the cell cycle. ROS promote sustained proliferation on one hand by inducing mutations of crucial cell cycle control genes such as proto-oncogenes, on the other hand by excessively activating signalling pathways leading to proliferation $[56,59]$.

ROS also play a role in the avoidance of growth suppressor mechanisms, which is another hallmark of cancer. One such mechanism is the suppression of proliferation by contact inhibition, which is believed to be important during wound healing and regeneration, and for which Ras and Ras-induced ROS levels have to be low. Overactivating mutations of ras elevate ROS levels and consequently result in a loss of contact inhibition [70]. Other cell-cyclerelated hallmarks in which ROS play a role are the resistance of apoptosis and the enabling of replicative immortality. ROS-induced mutations can downregulate tumour suppressor genes involved in cell death programs such as apoptosis and support cell death resistance, whereas unlimited replication capacities can be obtained by ROS signalling increased telomerase expression [56, 60, 70, 71].

Angiogenesis is crucial to maintain continuously-active tumour cells by delivering nutrients and oxygen to the growing cancer and removing waste products and carbon dioxide. In normal physiological processes (e.g. wound healing) angiogenesis is only transiently active, but during tumour progression new vessels are continuously growing. ROS directly promote angiogenesis by controlling the pro-angiogenic vascular endothelial growth factor A (VEGF-A) and by activating the transcription factors NF- $\mathrm{kB}$, AP-1 and STAT1 (signal transducers and activators of transcription family) [56, 69, 72, 73]. In doing so, ROS also support tumour invasion and metastasis to a secondary niche. ROS play additional roles in invasion and metastasis via supporting Met (MET protooncogene, receptor tyrosine kinase) overexpression and epithelial-mesenchymal transition (EMT), as well as 
through the creation of invadopodia (which degrade the extracellular matrix) or the recruitment and transformation of fibroblastic cells into carcinoma-associated myofibroblasts which secrete pro-invasive signals $[56,69,70,74$, 75].

ROS also link tumour-promoting inflammation and cancer. Inflammatory cells produce ROS which attract more inflammatory cells and lead to more ROS production [57]. Chronic inflammation is indeed strongly correlated with cancer incidence $[33,57]$. For example, colitis develops into colon cancer after inflammatory infiltration, increased production of ROS and impairment of antioxidant defences resulting in genetic and epigenetic alterations that promote cancer development [76]. On the other hand, exogenous-induced oxidative stress also leads to chronic inflammation. For example, cigarette smoke produces pro-oxidants, causing inflammation of the bronchus and eventually transformation of lung cells into malignant tumour cells $[33,57]$.

On top of their original six hallmarks, Hanahan \& Weinberg (2011) recently added two emerging hallmarks: deregulation of cellular energetics and avoidance of immune destruction. The deregulation of cellular energetics results from the metabolic reprogramming of cancer cells or, as recently suggested, of adjacent stromal fibroblasts [77-79]. This metabolic reprogramming, referred to as the Warburg effect, consists of an abnormal oxygen metabolism with high rates of aerobic glycolysis leading to lactate production instead of mitochondrial oxidative phosphorylation, even when ample oxygen is present [77-79]. In this process, cancer cells induce oxidative stress in neighbouring stromal cells, which elicits their autophagic cell death via activation of NF-kB and HIF-1 [80]. Autophagy in the stromal cells not only releases building blocks for cancer cells directly, it also reprograms the stroma metabolically, hence leading to the Warburg effect [79-81]. Hereby, additional high-energy mitochondrial fuels and biomass precursors (e.g. lactate, ketone bodies, fatty acids, and glutamine) are released to fuel the anabolic cancer cells $[79,80]$. Autophagy can thus work cytoprotective for growing tumours adapting to a stressful environment. However, it should be noted that autophagy has a dual role and can on the other hand also prevent carcinogenesis by removing damaged organelles such as mitochondria and, in this way reduce oxidative damage and genomic instability [82]. The hallmark for which the involvement of ROS is still uncertain is the evasion of cancer cells from immune destruction. It can be speculated that ROS activate the immune suppressor TGF- $\beta$ resulting in the inactivation of natural killer cells $[83,84]$. However, since administration of TNF blockers, which prevent TNF-induced ROS production, to patients with rheumatoid arthritis increased the risk for developing lymphomas, the contribution of ROS in avoiding immune destruction is still uncertain [85].

\subsection{ROS regulation in cancer cells and cancer stem cells}

\subsubsection{ROS and cancer cells}

Neoplastic cells have altered redox systems and produce more ROS than normal cells $[1,86]$. Chronically-elevated levels of endogenous ROS in cancer cells accelerate DNA damage and alter signalling pathways, leading to adaptive changes that play important roles in tumourigenesis, metastasis and drug resistance, and are correlated with a bad prognosis [1,87].

The mechanisms by which cancer cells increase ROS are diverse. They activate proto-oncogenes and oncogenes that upregulate ROS-producing enzymes, inactivate antioxidants or stimulate the metabolism [1, 85, 88-91]. For example, ras-transformed cells contain more superoxide via activation of NOX1 or inactivation of the antioxidant 
sestrin, which is required for anchorage-independent growth, morphological transformation and tumourigenicity [1, 70, 92, 93]. In addition, Ras itself is redox-regulated and activated by nitric oxide and, possibly, hydrogen peroxide [70]. Loss or reductions of tumour suppressor genes also induce a redox-imbalance and elevated ROS levels in many types of cancers. For example, a loss or decrease of $p 53$ disturbs its function in controlling genetic stability and in preventing cancer by regulating the expression of antioxidant genes such as GPX1, MnSOD and aldehyde dehydrogenase 4 (ALDH4) [1, 94]. In stromal fibroblasts, redox alterations resulting from a loss of $p 53$ is a key inducer of epithelial transformation and cancer invasion via RNS-mediated ICAM1 signalling [95]. The free radical production rate in cancer cells is also elevated by their increased glycolytic metabolism. Probably, high rates of glycolysis and a metabolic shift towards the production of lactate reflect a less efficient ATP production in the mitochondria and increases electron leakage from the respiratory chain [1, 81, 96-102]. The reason why cancer cells use this aerobic glycolytic metabolism for energy requirements is still under debate. It could be beneficial in the hypoxic tumour environment, created by extensive cell proliferation, unorganized vasculature and irregular blood flow. Mitochondrial dysfunction as a consequence of mitochondrial DNA mutations could also be responsible for respiratory inefficiency and could contribute to the Warburg effect [81, 96-101, 103].

While elevated ROS levels support tumour initiation, progression and promotion, they also increase the internal stress level and make the tumour more vulnerable to cell death. Therefore, a dynamic ROS regulation in tumour cells, which prevents cell death but suffices to stimulate cell survival and proliferation, is essential to induce malignant transformation, metastasis and chemoresistance $[1,70,86]$. Most cancer cells adapt to persistentlyincreased ROS levels by activating redox-sensitive transcription factors that upregulate ROS-scavenging enzymes and systems such as SOD, GSS (glutathione synthetase), and GSH [1]. Oncogenes like $K$-ras, B-raf and myc increase the resistance of cancer cells to oxidative stress by elevating the activity of the Nrf2 transcription factor, which increases ROS detoxification and upregulates various cytoprotective genes [1, 70, 86]. Deletion of Nrf2 reduces the possibility of K-Ras to induce proliferation and tumourigenesis, which supports the importance of ROS limitation in tumour outgrowth [86]. Human telomerase reverse transcriptases (hTERTs), the catalytic subunits of telomerase holoenzymes, reduce basal cellular ROS levels and endogenous ROS production in cancer cells, possibly through activation of NF- $\mathrm{KB}$, by increasing the ratio of reduced to oxidized glutathione, by recovering oxidized peroxiredoxin to its nonoxidized form, and by elevating the activity of cytochrome c oxidase [41]. Other strategies of cancer cells to avoid excessive oxidative damage include metastasis to escape ROS in the primary tumour site, and the Warburg effect to increase oxidant-resistance [70].

If cancer cells fail to keep ROS levels below a certain cell-death threshold, ROS induce cancer cell death via apoptosis, necrosis or autophagy, as has been reviewed by Gupta et al. [85]. The ability of cancer cells to distinguish between ROS as a survival or apoptotic signal depends on the concentration, duration, type and site of ROS production. For example, while modest ROS levels are required for the survival of cancer cells, excessive levels cause senescence-induced tumour suppression or cell death and while NOX-derived ROS in response to TNF $\alpha$ play a protective role, mitochondria-derived ROS promote apoptosis $[1,85,86]$.

\subsubsection{ROS and cancer stem cells}



stem cells. The hypothesis is that these tumour seeds are protected against DNA damage in order to facilitate the continuation of the tumour [1]. Cancer stem cells, also called tumour-initiating cells or tumour-propagating cells, are only a subset of the entire tumour population and share properties of self-renewal and chemo- and radioresistance with normal stem cells. They have an increased capacity to initiate and sustain tumour growth, which is important in the progression and the recurrence of malignant tumours [1, 100, 104-106]. Cancer stem cells also play an important role in tumour angiogenesis by vascular endothelial growth factor (VEGF) signalling [100]. Possibly, they are the source of all the tumour cells present in a malignant tumour [1, 100, 104-106].

Little is known about the redox balance of cancer stem cells. It is thought to resemble that of normal stem cells, given the importance of this balance in stem cell maintenance, self-renewal and differentiation $[1,70,100]$. Just as stem cells, cancer stem cells possess enhanced protection mechanisms against ROS-induced stress, which could explain their survival and drug resistance. In comparison with non-stem cancer cells, they have lower intracellular ROS levels due to increased expressions of free radical scavenging systems [1, 70, 104, 105]. For example, expression of the (cancer) stem cell marker CD44, and especially the isoform CD44v, protects cancer stem cells against high ROS levels in the tumour environment through stabilization of the glutamate-cysteine exchange transporter and the consequent stimulation of intracellular GSH. The removal of CD44v results in increased ROS levels and ROS-dependent p38 MAPK activation, making CD44v-targeted therapies that prevent ROS defence a potential approach to kill cancer stem cells $[1,100,106,107]$. The mechanisms of cancer stem cells to repair ROSinduced damage are also thought to differ from non-stem cancer cells, with possibly enhanced activation of DNA checkpoint kinases $[1,100]$. Tumour dormancy, which temporarily halts metastatic growth and is induced by p38 MAPK, represents another protection mechanism of cancer stem cells against oxidative stress. In high-ROS environments, dormant cancer stem cells survive injury and wait to expand the tumour in more favourable times and safer conditions [70].

470 Moderate hypoxia in the tumour environment also becomes increasingly related to the cancer stem cell phenotype

471

472

\section{ROS modulate the regeneration process}

In the previous section, we summarized the involvement of ROS in tumour initiation, growth and metastasis. To and is thought to be beneficial for the survival, self-renewal and tumour growth of cancer stem cells [1, 100]. In brain tumours, restricted oxygen conditions increase the cancer stem cell fraction and promote acquisition of a stem-like status [100]. Cells under hypoxia display increased markers associated with stem-like phenotypes such as CD44. It is hypothesized that the correlation of tumour hypoxia to poor patient outcome is related to an increase in the proportion of cancer stem cells. As such, therapies that disrupt the microenvironmental conditions of hypoxia may be critical in eliminating cancer stem cells [100].

In conclusion, we can state that it is crucial to determine molecular signalling pathways that maintain the redox state in cancer cells and cancer stem cells. By abrogating the cell's survival mechanisms against redox imbalances, the ability of redox-related therapies to halt cancer can be enlarged. highlight the dual role of ROS, we will also discuss their function in a normal physiological situation, i.e. regeneration. Regeneration and cancer share similar underlying events, but result in a different outcome (section 
3.1). As such, we will emphasize the redox-related aspects of the shared processes, among which cell proliferation, apoptosis and differentiation.

Regeneration is a complex concept, defined differently depending on the context. Regeneration covers processes from tissue repair to asexual reproduction. Basically, all these processes result in the same outcome, which is the recreation of damaged or lost cells, tissues, organs and even entire body parts without the formation of scar tissue and with complete functional integration [108]. Many organisms possess good regenerative capacities in early life stages, especially as embryos or larvae, but lose this ability during metamorphosis, puberty and ageing [109]. However, some organisms maintain excellent regenerative capacities throughout their adult lives, being able to regrow certain tissues, organs or even complete structures (limbs, lens, retina, spinal cord, brain, heart, and neurosensory cells) $[109,110]$. This lifelong ability to regenerate is widespread in the metazoan phyla, ranging from invertebrates such as flatworms, cnidarians (Hydra), Arthropoda and Asteroidea (star fish) to vertebrates including zebrafish, newts, clawed frog, axolotl and even mammals such as deer and spiny mice [110-113].

The regeneration process generally proceeds in three main phases: wound closure, cell proliferation/differentiation and growth [111, 112]. After injury, wound closure is characterized by muscle contractions, filament reorganization and the formation of a wound epithelium. In the second phase, new cells are necessary to re-establish the lost tissue or structure. An orchestra of perfectly timed signalling factors maintains a correct balance between cell proliferation, differentiation and apoptosis, guiding the acquired cells to their correct destination. All of these processes are subjected to the redox balance, although the exact function of the redox signature during regeneration is still being investigated. Many in vitro and in vivo studies already demonstrated the importance of ROS signalling in the context of neuroregeneration. For example, ROS production has been associated with neuronal differentiation in neuronal stem cells and with the induction of neurite outgrowth in hippocampal cell lines [114118]. Improved regenerative capacities of mechanosensory axons were discovered after an inactivating mutation in an extracellular peroxidase gene (i.e. pxn-2) in C. elegans, [119]. Rieger and Sagasti showed that increased hydrogen peroxide levels at the wound site are necessary for peripheral sensory axon regeneration following skin injury in zebrafish larvae and that an inhibition of DUOX 1 resulted in impaired fin regeneration [120]. Lately more and more publications indicate the importance of ROS signalling for successful regeneration of complete body structures [121-123]. Both Love and Gauron [121, 122] published in Nature about the importance of a ROS burst at the wound site for proper tail and fin regeneration of Xenopus tadpoles and zebrafish, respectively [121, 122].

It is hypothesized that ROS signalling modulates the regeneration process through the regulation of three crucial cellular processes: proliferation, apoptosis and differentiation. Perfect orchestration of these processes results in the formation of a blastema, a regenerative structure of newly differentiated cells that will give rise to the newly formed structure [112]. ROS are necessary for blastema formation, since an inhibition of ROS production results in a significant reduction in the blastema size as well as a diminished number of mitotic cells after the inhibition of ROS production. Love and colleagues investigated the signalling pathways controlling cell proliferation, and showed that increased ROS levels are necessary for the activation of the Wnt/ $\beta$-catenin signalling pathway, which confers polarity and controls cell fate, as well as for one of its main downstream targets, fgf20, during posterior regeneration $[122,124,125]$. During the developmental process, activation of the Wnt/ $\beta$-catenin pathway via ROS signalling is modulated through NRX, a small redox-sensitive protein (see 1.4.1: ROS \& patterning). It is likely 
that ROS-induced activation of the Wnt/ $\beta$-catenin signalling pathway during regeneration also acts via NRX. However, this has yet to be confirmed.

Apoptosis is a redox-controlled process and Gauron and collegues were the first to link ROS production and the induction of cell death in a regenerative context [121]. They showed that NOX inhibition reduces the number of apoptotic cells and inhibits JNK activation. Exposure to inhibitors of ROS production, apoptosis, and JNK all significantly reduce the number of proliferative cells and lead to impaired regeneration. These data suggest that ROS signalling is necessary for the activation of the cell death process and JNK cascade, which work in parallel to coordinate successful regeneration. MAPKs also influence cell differentiation. For example, during planarian regeneration, JNK and ERK regulate the differentiation process. Inhibition of these enzymes blocks the cell cycle and results in a reduced blastema formation [126-129]. Although MAPKs are shown to be redox-controlled in various cellular and physiological processes, it still needs to be clarified whether ROS are the upstream triggers of MAPK activation during regeneration.

Both ROS production and innervation seem to be crucial factors to achieve successful regeneration. However, little is known about the crosstalk between both signalling processes [130, 131]. It has been shown that ROS regulate neuroregeneration and differentiation [114-120]. Nevertheless, the question remains whether the general impairment of the regeneration process is a direct result of ROS inhibition or if it is induced through the inhibition of neuroregeneration and a lack of innervation. Removal or manipulation of nerve cords leads to incorrect regeneration in various invertebrate and vertebrate organisms [132, 133]. For example, Endo demonstrates the importance of the nervous system during newt ectopic limb regeneration and shows that denervation before amputation/injury or in the early phase of blastema formation induces regression of the blastema and inhibits successful regeneration [111]. To find the answers concerning the cross-talk between the redox balance and the nervous system, more information must be gathered about the molecular mechanisms through which they both regulate the regeneration process. Different regulation and activation of redox-associated pathways, including the MAPK cascades, result in dissimilarities in neuroregenerative capacities between peripheral neurons, which have the ability to regenerate after injury in most invertebrate and vertebrate organisms [134, 135]. Considering their importance in the regulation of cell proliferation, differentiation, survival and migration, it is not surprising that in various carcinogenic conditions, deregulation of the MAPK pathways is observed (discussed in the introduction section) [31]. Studying redox-controlled pathways that regulate the regeneration process and carcinogenesis, including the MAPK cascades, will provide crucial information to improve ROS-related therapies.

\subsection{Regeneration and cancer: following similar pathways to different destinations}

Cell proliferation, differentiation, death and migration are important processes during both regeneration and cancer. While they are well coordinated during the regeneration of lost body parts, which is a normal physiological process, the disease cancer is characterized by an uncontrolled execution of these processes and a failure to heal. The initial signals, such as the capacity to sense damage and activate cell proliferation, are most likely unimpaired, while the later events of regeneration, including tissue formation, remodelling, and the production of termination signals, are lost during cancer [61, 108]. The regenerative environment is therefore suggested to suppress carcinogen-induced malignant transformation [61, 108]. Animals with high regenerative capacities, such as 
urodeles and planarians, functionally repair induced damage and regenerate over and over without malignant transformations [108, 136, 137]. Newts, for example, successfully regenerate limbs and lenses many times over a relatively short period, and even when chemical carcinogens are injected locally within the newt eye during lens regeneration, the dorsal iris (capable of lens regeneration) does not form abnormal cells and is resistant to tumour formation. On the contrary, in the ventral iris (non-regenerating) an exposure to carcinogenic compounds results in abnormal cells that give rise to aggressive tumours [61, 108]. This was again confirmed in the planarian Dendrocoelum lacteum, in which carcinogenic exposure of regenerating tissues induced mild differentiated hyperplasia, whereas infiltrating tumours emerged in non-regenerating tissues. The regenerating tissue was even able to reverse malignancies into differentiated structures and regain morphostasis [61, 108, 136, 137]. Although the absolute numbers of cell division in newt or planarian regeneration do not reach those seen during normal cellular turnover of, for example, mammalian skin over a lifetime, potent tumour suppressive functions must be present during the regeneration process of these organisms. However, as the entire organism remains susceptible to cancer, though often with a lower incidence, the ability to control tissue morphogenesis and impair unrestrained proliferation and tumour formation seems to be a property of actively regenerating tissues and their microenvironment [61]. In the highly regenerative mammalian liver, 95\% of carcinogen-induced tumours also remodel into normal tissue [137]. Thus, fundamental differences between regeneration and cancer lie in the coordination of responses and in gene expression patterns rather than in structural or species-specific capacities $[108,138]$. Indeed, the underlying molecular and cellular mechanisms of these processes display a lot of similarities. Between renal regeneration and repair and renal cell carcinoma for example, $77 \%$ of the differentially changed genes were found to be concordant [138]. Therefore, a comparison of regenerative and carcinogenic processes could reveal redox-controlled pathways that regulate, co-regulate or initiate cell proliferation, differentiation, death and migration. In the next paragraphs, common redox-controlled molecular, cellular and mechanistic contributors of both events will be discussed. A special emphasis will be put on stem cells. These cells are important for regeneration and can transform into cancer stem cells which are essential in the building and supporting of tumour microenvironments, in providing metastatic niches and in maintaining cancer hallmarks [99, $139,140]$.

\subsubsection{Genes}

Perhaps one of the best characterized groups of genes which link cancer with regeneration is the family of tumour suppressor genes. These genes regulate proliferation-dependent and possibly also proliferation-independent aspects of regeneration [61]. Tumour suppression may therefore be an ancestral mechanism which surveys changes in the environment, such as loss of tissues, to orchestrate the appropriate proliferation and differentiation responses that are needed (wound repair or regeneration) while suppressing tumourigenesis [54, 61]. Abundance of these regulatory molecules permits cell cycle re-entry from a quiescent state in early life stages, but works restrictive as the organism ages, thereby limiting its regenerative abilities [109]. The function of tumour suppressors varies with developmental stage and age within a species, and variable components are present in different species. Important tumour suppressors involved in carcinogenesis and regeneration programs are Rb, p53, PTEN and Hippo. Rb and p53 prevent inappropriate proliferation and eliminate or enable repair of stressed or genome-damaged cells, which is important for ensuring a healthy and tumour-free regenerate [61]. A crucial role of $\mathrm{Rb}$ in the transition from a proliferative to a post-mitotic differentiated state has been demonstrated in developmental studies in mice, where 
the absence of $\mathrm{Rb}$ resulted in a failure of organized haematopoiesis, neurogenesis and myogenesis [141, 142]. Regulation of p53 is critical for proper limb regeneration in salamanders [143], imaginal disc regenerative potential in Drosophila [144] and in axonal and liver regeneration in mice [145, 146]. The tumour suppressors PTEN and Hippo are important in restraining and organizing tissue growth [61]. PTEN is an important negative regulator of the PI3K signalling pathway, which constrains cell size, cell number and survival and is among the most frequently inactivated tumour suppressor genes in human cancer $[147,148]$. PTEN-dependent pathways are involved in axon regeneration after injury and control $\beta$-cell regeneration in aged mice $[149,150]$. In planarians, PTEN deficiency results in the impairment of stem cell differentiation and inhibits regeneration [151]. The Hippo signalling pathway is a more-recently-identified growth control pathway, which negatively regulates yorkie or its mammalian homolog YAP (yes-associated protein 1) which is overexpressed in various cancers [61, 152, 153]. During intestinal regeneration, the Hippo pathway controls YAP to allow compensatory proliferation while preventing malignant transformation [153]. A knockdown of the Hippo pathway in the flatworm Macrostomum lignano results in aberrant regeneration [154].

Other genes important in both cancer and regeneration are EGFR encoding genes. EGFRs regulate biological processes such as cell proliferation and differentiation and are important in carcinogenesis to support tumour growth, differentiation, survival and angiogenesis [155-158]. This signalling pathway is also required in regeneration, for example in adult midgut epithelial regeneration in Drosophila and liver regeneration in mice $[159,160]$. Silencing of EGFRs during regeneration of the planarian Schmidtea mediterranea resulted in smaller blastemas, abnormal differentiation of cephalic ganglia, decreased regeneration of eye pigment cells and abnormal pharynges and mouth openings [155]. Examples of other interesting genes and pathways involved in both processes are $\beta$-catenin [161-163], mTOR [164], the transforming growth factor $\beta$ (TGF $\beta$ )/bone morphogenetic protein (BMP) and JAK/STAT [155].

\subsubsection{Mechanisms}

Cancer and regeneration are not only linked at the molecular level, they also share common mechanisms and pathways. Important mechanisms during cancer and regeneration are the epithelial-mesenchymal transition (EMT) and the reverse mesenchymal-epithelial transition (MET). These processes are active in various types of cancer and during wound repair and tissue regeneration of adult tissues [66, 165-167]. A critical molecular event during EMT is the loss of E-cadherin, a key component of adherens junctions. This loss releases $\beta$-catenin into the cytosol and elicits activation of the canonical Wnt signalling pathway, again important in both regeneration and cancer $[163,165]$.

Secondly, disturbances in gap junction-permeable signals and gap junction-mediated cell communication play a role in carcinogenesis and are linked with developmental and regeneration disorders during embryonic morphogenesis [137, 168-171]. In mice, the expression of specific connexins is upregulated during skeletal muscle regeneration [104]. Regenerating planarians exposed to gap-junction blockers regenerate two heads [172, 173].

It has long been known that the immune system and inflammation are linked with cancer, but recently more and more research also illustrates the importance of the immune system in the regeneration process [174-178]. Cells of the immune system remove damaged cells and cell debris, produce signalling and growth factors, regulate angiogenesis and modulate the extracellular matrix environment in the first stages after injury. Herein, ROS play 
a crucial role, acting both as antimicrobials as well as signalling molecules [5]. Loss of immune cells, such as macrophages, results in impaired regeneration [176, 177]. In addition, there is a reverse correlation between immunity and regeneration abilities, since a decreased regenerative capacity was linked with the maturation of the immune system in various vertebrate organisms [178, 179].

Regeneration and carcinogenesis share many similarities as to redox-controlled processes and mechanisms, yet have different outcomes (Fig. 3). Now the question arises: can ROS be the controlling "agents" we are looking for to overcome or even avoid cancer formation? A redox burst initiates and regulates both wound healing and regeneration. After the regeneration process is completed, ROS levels decrease until normal physiological levels are reacquired. Altered ROS levels are also observed during carcinogenesis, but the redox balance remains disturbed throughout the entire duration of tumour formation [180]. Unfortunately, it is not a simple prolonged redox status that leads to cancer. Although many cancer treatments based on alterations in the redox balance produce successful results, they often lack specificity and have damaging side effects on healthy tissues. Knowing the similarities and differences in redox control between regeneration and carcinogenesis will open doors to the fine-tuning of pre-existing therapies and the development of novel diagnostic and therapeutic targets not only to overcome, but also to prevent tumour development (Fig. 3).

\section{Redox-related anticarcinogenic targets in regenerative mechanisms}

\subsection{Direct redox-related anticarcinogenic targets}

The different redox signature of cancer cells and non-cancer cells is an opportunity to selectively target cancer cells with redox-based cancer therapies (Fig. 3). Both ROS-elevating and -eliminating strategies have been developed against cancer cells, since modest ROS levels enable tumour growth and survival, while excess levels inhibit tumour cell proliferation and induce apoptosis, autophagy and necrosis. These strategies are reviewed by Gupta et al. [85], Glasauer et al. [181] and Wondrak et al. [182].

Pro-oxidant based therapies elevate ROS levels by using ionizing radiation, ROS-generating chemotherapeutic agents or agents that interfere with the antioxidant system. They are based on the fact that cancer cells already possess elevated ROS levels and that a further increase in ROS will induce a redox shift resulting in cancer cell death, the inhibition of cancer cell proliferation or motility. Since normal cells generally have higher capacities to cope with additional ROS-producing insults than cancer cells, it is possible to preferentially accumulate ROS in cancer cells and kill them selectively [1, 33, 85, 87, 182-184]. ROS-depleting strategies, on the other hand, decrease ROS levels by using antioxidants, enhancers of ROS scavenging enzyme activities or NOX inhibitors. They are based on the fact that ROS signalling is important in cancer cell proliferation and that a disturbance of this signalling inhibits tumour growth. Most strategies, however, work through ROS generation and the consequent induction of cell death $[1,33,85,183,184]$. Table 1 represents a few of the most described therapeutic procedures of ROS elevating and eliminating strategies, which will be briefly illustrated below.

\subsection{1. $\quad$ ROS elevating strategies for cancer therapy}


One of the main strategies of ROS-elevating therapies is pushing the cancer cells into cell death. A subdivision is made between agents that elevate ROS directly and agents that interfere with the antioxidant system (Table 1). Procarbazine, for example, was one of the first drugs developed based on its hydrogen peroxide production and is approved for the treatment of Hodgkin's lymphoma, non-Hodgkin's lymphoma, malignant melanoma and for primary brain tumours (Table 1) $[85,185,186]$. Other ROS-generating compounds not mentioned in table 1, but

680

681

682

683

684

685

686

687

688

689

690

691

692

693

694

695

696

697

698

699

700

701

702

703

704

705

706

707

708

709

710

711

712

713 also used in cancer therapy or promising as novel therapeutic agents are, among others, imexon [187], elesclomol 273 [182, 188], bufalin [189], the natural alkaloid piperlongumine [190-194], hirsutanol A [183, 195, 196], the fatty acid derivative trans-10, cis-12 conjugated linoleic acids [183, 197, 198], andrographolide [199-201], emodin [202-204] c-phycocyanin [33, 205], bortezomib [206] and the vitamin E analogue tocopheryl succinate [33]. They mainly induce apoptotic cancer cell death, but also affect cancer cell proliferation, angiogenesis and metastasis

Aside from ROS-generating compounds, radiotherapy also uses ROS to eliminate cancer cells as demonstrated in a number of preclinical and clinical studies [85]. Furthermore, there are also many promising chemotherapeutic agents that indirectly increase ROS levels as well, which can lead to apoptosis, inhibition of angiogenesis and metastasis, or reduced proliferation in various cancers (Table 1).

Besides being used as monotherapy, ROS-generating agents are currently combined with chemo- and radiotherapy to increase the vulnerability of cancer cells to these treatments $[85,146]$. The nutraceutical curcumin possesses both antioxidant and pro-oxidant activities, depending on the concentration and cancer type, and induces ROSdependent inhibition of proliferation as well as death of chemoresistant cells by sensitizing them to chemotherapy $[85,182,207]$. A combination of curcumin with tamoxifen correlates with an increase in ROS generation and results in synergistically induced cell death, both apoptosis and autophagy, in chemoresistant melanoma cells, without affecting noncancerous cells [208]. Other potential therapies that are used to sensitize chemo- or radioresistant cancer cells via ROS generation include triptolide [209], 2-methoxyestradiol [210], emodin [211], D-allose [212], withaferin A [213], and $\mathrm{As}_{2} \mathrm{O}_{3}$ [214].

\subsubsection{ROS eliminating strategies for cancer therapy}

Agents with the potential to inhibit ROS generation are currently under development or used as cancer therapy, although less frequently than ROS-elevating agents. These agents induce cancer cell death, suppress proliferation, angiogenesis or metastasis. As for the ROS-elevating strategies, ROS can be eliminated directly or by acting upon the antioxidant system (Table 2). The effectiveness of ROS-decreasing therapies in cancer treatment is demonstrated in experimental studies in which overexpression of MnSOD decreases the proliferation of androgenindependent human prostate cancer cells. Overexpression and/or delivery of other compounds of the antioxidant system, such as glutathione peroxidase, catalase or SOD enzymes, has likewise been proven to be effective in animal models (Table 2) [215-218]. ROS scavengers, such as the precursor of cysteine glutathione, N-acetylcysteine (NAC), have also been proven to be effective as NAC is correlated with a decreased proliferation of glioma cells (Table 2) [219]. A direct reduction of ROS production, for example via the inhibition of NOX enzymes, similarly increases apoptosis, as shown in prostate and pancreatic cancer cells, and inhibits angiogenesis and cancer cell invasion (Table 2) [88, 220-222]. 
Given the importance of a balanced redox state in the regulation of proliferation, cell death and migration, antioxidant therapies are also incorporated into conventional chemotherapeutic or radiation treatment protocols to scavenge therapy-induced ROS and, in this way, protect healthy cells and tissues [85, 223, 224]. Amifostine is an example of such a free-radical scavenger drug that protects normal but not malignant cells against therapy-induced ROS [225].

In conclusion, despite all the positive effects of redox-based therapy on tumours, there are still some major concerns regarding their use [87, 181, 182]. First of all, as ROS regulate numerous signalling pathways, these therapies can therefore be toxic for the surrounding tissues where they generate ROS-induced off-target effects on the proliferation, migration and survival of healthy cells. As such, combinatorial antioxidant therapies that serve as cytoprotective adjuvants are used to prevent cancer therapy-associated organ toxicity [182, 226]. Secondly, ROS-induced biochemical and molecular changes may contribute to the emergence of drug resistant machineries of cancer cells during disease progression. For example, increased resistance of multi-drug resistant leukaemia cells to cytotoxic effects of hydrogen peroxide was found to be mainly caused by elevated catalase levels. The resistance of bladder cancer cells to arsenic trioxide was associated with elevated SOD activity and reduced GSH content [85]. Thirdly, improvident interference with the redox balance can have undesirable outcomes. For example, while antioxidant supplementation reduces ROS and DNA damage, it prevents p53 activation and increases tumour cell proliferation and tumour growth in mice [227]. Finally, the heterogeneous cell population of tumours, consisting of cancer cells and cancer stem cells with different redox states, impedes a general redoxaltering approach. To tackle these problems, we should obtain further insights into redox-related signalling pathways and regulatory networks that control cell proliferation, death and migration. A combination of direct redox-altering therapies with therapies that target indirect redox-related processes can enhance drug efficiency and specificity. In this regard, interesting targets can be searched within the regeneration process, in which cell proliferation, death and migration are efficiently controlled and, presumably, redox-regulated.

\subsection{Indirect redox-related anticarcinogenic targets}

The redox state not only affects cell proliferation, death, and migration directly, it also alters these processes indirectly through the regulation of molecular or systemic pathways. In the following sections, we will focus on the indirect redox-related targets that are promising for anticarcinogenic therapies.

\subsubsection{Cellular redox-related targets}

\section{Tumour suppressor genes as therapeutic targets}

Probably one of the most studied tumour suppressor genes in cancer research is p53. This tumour suppressor and nuclear transcription factor is important for the induction of cell cycle arrest, as well as for DNA repair, senescence, apoptosis, autophagy and the metabolism [228-230]. In most tumours p53 is hijacked, either by mutations or deletions that disrupt its DNA-binding activities and prevent the consequent transcriptional transactivation of target genes, or by posttranslational modifications or cytoplasmic sequestrations that disturb p53 activity [228, 230, 231]. In addition, inactive p53 pathways in cancer cells are associated with a higher resistance to conventional 


\begin{tabular}{|c|c|c|c|c|c|}
\hline & & \multirow{2}{*}{\multicolumn{2}{|c|}{ Compound }} & \multirow{2}{*}{ Therapeutic use } & \multirow{2}{*}{ References } \\
\hline & & & & & \\
\hline \multirow{11}{*}{$\begin{array}{c}\text { ROS } \\
\text { ELEVATING } \\
\text { STRATEGY }\end{array}$} & \multirow{3}{*}{ Direct agents } & $\mathrm{H}_{2} \mathrm{O}_{2}$ production & Procarbazine & $\begin{array}{c}\text { (non)-Hodgkin's } \\
\text { lymphoma, malignant } \\
\text { melanoma, primary brain } \\
\text { tumours }\end{array}$ & $\begin{array}{c}{[85,185,} \\
186]\end{array}$ \\
\hline & & $\begin{array}{c}\text { Production of superoxide } \\
\text { anions via NOX } \\
\text { activation }\end{array}$ & $\begin{array}{l}\text { Parthenolide and } \\
\text { its analogue } \\
\text { dimethylaminopar- } \\
\text { thenolide }\end{array}$ & $\begin{array}{l}\text { Induction of apoptosis } \\
\text { and growth suppression in } \\
\text { prostate cancer, primary } \\
\text { leukaemia, osteosarcoma, } \\
\text { melanoma and triple- } \\
\text { negative breast cancer }\end{array}$ & $\begin{array}{l}{[85,182,} \\
232,233]\end{array}$ \\
\hline & & $\begin{array}{l}\text { Elevation of superoxide } \\
\text { levels by impairing } \\
\text { mitochondrial electron } \\
\text { transport chain }\end{array}$ & Arsenic trioxide & $\begin{array}{l}\text { Used for treatment of } \\
\text { leukaemia }\end{array}$ & $\begin{array}{c}{[1,85,182,} \\
184,234, \\
235]\end{array}$ \\
\hline & \multirow{8}{*}{$\begin{array}{c}\text { Agents } \\
\text { interfering with } \\
\text { the antioxidant } \\
\text { system }\end{array}$} & Thioredoxin inhibitor & $\begin{array}{l}\text { Motexafin } \\
\text { gadolinium }\end{array}$ & $\begin{array}{l}\text { Induces apoptosis; in trial } \\
\text { for chronic lymphocytic } \\
\text { leukaemia (phase II) and } \\
\text { non-small cell lung cancer } \\
\text { with brain metastasis } \\
\text { (phase III) }\end{array}$ & $\begin{array}{l}{[85,182} \\
184,236]\end{array}$ \\
\hline & & $\begin{array}{l}\text { GSH inhibition via y- } \\
\text { glutamylcysteine } \\
\text { synthetase inhibition }\end{array}$ & $\begin{array}{c}\text { Buthionine } \\
\text { sulfoximine (BSO) }\end{array}$ & $\begin{array}{l}\text { Combined with arsenic } \\
\text { trioxide for treatment of } \\
\text { advanced solid tumours }\end{array}$ & $\begin{array}{l}{[85,237-} \\
241]\end{array}$ \\
\hline & & $\begin{array}{l}\text { GSH inhibition via } \\
\text { inhibition of GPX and } \\
\text { GSH conjugations }\end{array}$ & $\begin{array}{c}\beta- \\
\text { phenylethylisothio- } \\
\text { cyanate (PEITC) }\end{array}$ & $\begin{array}{c}\text { Selectively induces } \\
\text { cancer cell death while } \\
\text { being less toxic to normal } \\
\text { cells }\end{array}$ & $\begin{array}{c}{[1,33,85} \\
182,239- \\
244]\end{array}$ \\
\hline & & SOD1 inhibition & ATN-224 & $\begin{array}{c}\text { Inhibits cancer cell } \\
\text { proliferation and } \\
\text { metastasis. Phase II trial } \\
\text { for recurrent prostate } \\
\text { cancer, solid tumours, } \\
\text { multiple myeloma and } \\
\text { resistant malignancies in } \\
\text { vitro }\end{array}$ & $\begin{array}{l}{[1,33,85} \\
182,239 \\
242-246]\end{array}$ \\
\hline & & SOD1 inhibition & 2-methoxyestradiol & $\begin{array}{l}\text { Phase I trial for metastatic } \\
\text { breast cancer, phase II for } \\
\text { prostate cancer }\end{array}$ & $\begin{array}{l}{[85,182} \\
245,246]\end{array}$ \\
\hline & & \multirow{3}{*}{$\begin{array}{c}\text { Chemotherapeutic agents } \\
\text { that also increase ROS } \\
\text { levels }\end{array}$} & $\begin{array}{c}\text { Garlic } \\
\text { diallyldisulfide \& } \\
\text { diallyltrisulfide }\end{array}$ & $\begin{array}{l}\text { Cell cycle arrest and } \\
\text { apoptosis in colon and } \\
\text { lung cancer }\end{array}$ & $\begin{array}{c}{[182,247} \\
248]\end{array}$ \\
\hline & & & $\begin{array}{l}\text { Dasatinib + } \\
\text { oxaliplatin } \\
\text { combination }\end{array}$ & $\begin{array}{l}\text { Reduce proliferation and } \\
\text { angiogenesis in colon } \\
\text { cancer cells }\end{array}$ & [249] \\
\hline & & & $\begin{array}{c}\text { Theaflavins and } \\
\text { berberine }\end{array}$ & $\begin{array}{l}\text { Inhibition of the } \\
\text { metastatic potential }\end{array}$ & {$[250,251]$} \\
\hline
\end{tabular}




\begin{tabular}{|c|c|c|c|c|c|}
\hline & & & & & \\
\hline & & Mechanism & Compound & Therapeutic use & References \\
\hline \multirow{9}{*}{$\begin{array}{c}\text { ROS } \\
\text { ELIMINATING } \\
\text { STRATEGY }\end{array}$} & \multirow[t]{2}{*}{ Direct } & \multirow[t]{2}{*}{ ROS suppressors } & $\begin{array}{l}\text { Inhibitors of ROS- } \\
\text { generating NOX } \\
\text { enzymes }\end{array}$ & $\begin{array}{l}\text { Increase in apoptosis of } \\
\text { pancreatic and prostate } \\
\text { cancer cells and decrease } \\
\text { in angiogenesis and } \\
\text { invasion }\end{array}$ & $\begin{array}{c}{[88,220-} \\
222]\end{array}$ \\
\hline & & & XQ2 & $\begin{array}{l}\text { Growth inhibition of non- } \\
\text { small-cell lung carcinoma }\end{array}$ & [252] \\
\hline & \multirow{7}{*}{$\begin{array}{l}\text { Via the } \\
\text { antioxidant } \\
\text { system }\end{array}$} & $\begin{array}{l}\text { Overexpression of } \\
\text { MnSOD }\end{array}$ & \multirow{2}{*}{\multicolumn{2}{|c|}{$\begin{array}{l}\text { Experimental studies: decrease in proliferation } \\
\text { of androgen-independent human prostate cancer } \\
\text { cells }\end{array}$}} & \multirow{2}{*}[215,216]{} \\
\hline & & $\begin{array}{l}\text { Overexpression of } \\
\text { gluthatione peroxidase }\end{array}$ & & & \\
\hline & & $\begin{array}{c}\text { Transgenic } \\
\text { overexpression/delivery } \\
\text { of catalase }\end{array}$ & $\begin{array}{r}\text { Reduced tumour } \\
\text { metastatic breast } \\
\text { metastasis to liver, }\end{array}$ & $\begin{array}{l}\text { ggressiveness in mouse } \\
\text { incer model/inhibition of } \\
\text { ung and peritoneal organs }\end{array}$ & $\begin{array}{c}{[217,253,} \\
254]\end{array}$ \\
\hline & & $\begin{array}{c}\text { Delivery of PEG- } \\
\text { conjugated SOD enzymes }\end{array}$ & $\begin{array}{r}\text { Inhibits peroxidat } \\
\text { gro }\end{array}$ & $\begin{array}{l}\text { ond metastatic tumour } \\
\text { th in mice }\end{array}$ & [218] \\
\hline & & \multirow{3}{*}{ Antioxidants (scavengers) } & Fullerene & $\begin{array}{l}\text { Inhibition of growth and } \\
\text { metastasis in a mouse } \\
\text { breast cancer model }\end{array}$ & [98] \\
\hline & & & $\mathrm{N}$-acetyl-cysteine & $\begin{array}{l}\text { Decreased proliferation of } \\
\text { glioma cells }\end{array}$ & [219] \\
\hline & & & Amifostine & $\begin{array}{l}\text { Protects normal but not } \\
\text { malignant cells against } \\
\text { therapy-induced ROS }\end{array}$ & [225] \\
\hline
\end{tabular}

Table 2: Overview of direct redox-related anticarcinogenic strategies eliminating ROS

chemo- and radiotherapy $[228,231,255]$. Therefore, reactivating suppressed p53 or rescuing mutant p53 in tumours may trigger lethality or permanent growth arrest in p53-deficient cancer cells, which is a promising strategy for successful anticancer treatment. Since p53 also protects normal tissues against off-target effects of cancer therapies, p53 restoring therapies also bypass deleterious side effects resulting from most of the current cancer treatments [228, 231, 255, 256]. For many years now, the modulation of p53 for cancer therapy is a very active area of research [255]. For example, wild-type p53 functions in humans are restored via the use of virusmediated p53 gene replacement $[231,255,256]$. Adenovirus-based p53 gene therapies have been approved by the Chinese government for the treatment of head and neck carcinomas, in which p53 mutations are frequent and increase with progression of the disease [231, 256]. Another way to restore p53 function is by pharmacologically activating wild-type p53, for example by blocking murine/human double minute 2 (MDM2) or its human counterpart HDM2, negative regulators of p53 stability. HDM2 is overproduced in many human tumours as a mechanism to restrict p53 function, leading to inefficient growth arrest and apoptosis. The small molecule compound RITA (reactivation of p53 and induction of tumour cell apoptosis) and the nutlin RG7112 are examples 
of compounds that activate 53 via these regulators and induce apoptosis and cell cycle arrest specifically in cancer cells without initiating DNA damage in normal cells [229, 231, 255, 256]. A restoration of the wild-type conformation and DNA binding capacities of mutant p53 is achieved by systemic administration of PRIMA-1 (p53 reactivation and induction of massive apoptosis) and its structural analogue PRIMA-1Met (APR-246), which induce apoptosis and inhibit tumour growth in vivo with a high degree of target specificity [228, 231]. Both compounds have been tested in primary leukemic cells from acute myeloid leukemia and chronic lymphocytic leukemia patients and APR-246 is being tested in a phase I clinical trial of patients with haematological malignancies or prostate cancer [256]. Other treatments that target p53 are reviewed by Chen et al. [231].

Limitations of p53-based cancer treatments are reviewed by Miryazans et al. [257] and include the indirect targeting of downstream effectors of the p53 pathway, which could interfere with the therapy efficiency or even worsen the outcome. For example, p21, a downstream target in the p53 pathway, induces cancer cell senescence, which is thought to trigger the secretion of growth-stimulating and metastasis-inducing factors. By targeting p53, p21-induced senescence could promote the growth of neighbouring cancer cells. For the same reason, tumour cell heterogeneity, which results into a wide variety of responses within a tumour, could limit p53-based cancer treatments. A last critical challenge of p53-targeted therapies is the elimination of cancer stem cells that drive abnormal tumour growth and exhibit a high resistance to cytotoxic effects of therapeutic agents. Especially at advanced stages, the high-genetic plasticity of human tumours increases the chance for acquired resistance to most single-agent therapies. Therefore, combinatory approaches in cancer therapy are often necessary and are extensively sought after. Since p53 is regulated in a redox-dependent manner and exerts its effects on cell proliferation and cell death via regulation of the cellular redox state, combinatorial therapies that target the redox balance could improve their efficiency. Redox-related anticarcinogenic targets and their effects on stem cells should be studied within the controlled environment of regeneration [228, 256].

\section{Signalling pathways as a therapeutic target}

Many signalling pathways that regulate cell proliferation, cell death, differentiation and migration are controlled by the cellular redox state. As such, the redox-regulated transcription factors HIF-1, NF- $\mathrm{KB}$, and Nrf2 are potential therapeutic targets considering their roles in malignant tumour progression. A subunit of HIF, named HIF-1 $\alpha$, supports cancer cell proliferation and chemoresistance and inhibitors of this subunit, such as PX-478, are currently tested in clinical trials for anticancer activities [182]. NF- $\mathrm{kB}$ is also activated in various types of cancer and regulates proliferation, suppression of apoptosis and migration. NF- $\mathrm{\kappa B}$ induces dedifferentiation of non-stem cells through modulation of the Wnt signalling pathway, resulting in the acquirement of tumour-initiating capacities. Inhibitors of the NF-kB pathway, including IKK blockers (BAY-11-7082, BAY-11-7085, MLN120B), proteasome inhibitors (Bortezomib) and NF-KB DNA-binding inhibitors (SN-50), are currently in clinical use as cancer chemotherapeutics, whereas others are undergoing clinical development and trials [258-261]. Nrf2 controls the antioxidant defence system and promotes protection of cells against ROS-induced damage, thereby decreasing the incidence of tumour initiation. In this context, Nrf2-related factors are potential chemopreventive targets [262, 263]. On the other hand, Nrf2 protects cells against apoptosis and inhibition of this factor, for example through ingestion of active stilbenes in fruits and vegetables, induces cell death in malignant cells [264]. 
ROS not only directly target transcription factors, they also influence their activation through interference with various signalling pathways. Alterations in signalling pathways such as MAPK cascades caused by abnormal activation of receptor tyrosine kinases or gain-of-function mutations are observed in different types of cancer [265, 266]. These redox-regulated proteins are good potential targets for cancer treatment and various small molecule inhibitors have been developed and are currently being tested in clinical trials [265, 267]. Inhibition of Ras, the upstream activator of the ERK MAPK pathway, did not provide promising results, probably due to the nonspecificity of these inhibitors. However, inhibition of MEK 1/2 or RAF both show interesting results as potent anticancer therapeutics and many manufacturers are working to produce inhibitors with high specificity and selectivity for different MAPK isoforms [31]. The possible inhibitors of the Ras/ERK MAPK signalling pathway which are currently investigated are reviewed in detail in Santarpia et al. [265]. Not only the ERK pathway, but also the p38 MAPK and JNK pathways offer interesting targets since they regulate apoptosis, cell proliferation, and the inflammatory response. Just as with the direct redox-related targets, combinatorial treatment with these therapies might trigger cancer cell death or increase the sensitivity of tumour cells to other therapeutic agents [31]. A possible reverse strategy is the activation of p38 MAPK, since this might sensitize the malignant cells to apoptosis. Caution is however necessary since this activation might enhance the inflammatory response and possibly cancer progression.

EGFR signalling is another redox-controlled signalling cascade involved in cell cycle progression [268-271]. Anticancer therapies frequently target mutated EGFR kinase, and inhibit processes involved in tumour growth and progression [269, 270]. A number of monoclonal antibodies directed against its extracellular ligand-binding domain were developed. For example, cetuximab and panitumumab block ligand-induced EGFR tyrosine kinase activation, leading to inhibition of cellular proliferation and induction of apoptosis [269, 270].

The applied strategy (which signalling factor/pathway should be activated or deactivated) depends on the cancer type and stage. A combination of these indirect redox-related therapies with existing redox-altering therapeutics can enhance their efficiency. The precise control of cell proliferation, death and migration via these signalling pathways during the regeneration process provides an interesting context to study the impact of redox interference through these cascades on these processes. This knowledge will guide us towards the correct use of these targets or discovery of new targets as anticarcinogenic therapeutics.

\section{Telomerase}

In $80-95 \%$ of the cancers, telomerase is overexpressed. Telomerase protects cancer cells against DNA damage, cell senescence and the consequent induction of apoptosis, and as such promotes tumour growth. This enzyme is also activated in adult stem cells during planarian regeneration [272]. This makes telomerase an ideal candidate target for anticancer therapeutics. Several inhibiting strategies are being tested, including small molecule inhibitors, antisense oligonucleotides, immuno- and gene therapies targeting the hTERT or hTER, G-quadruplex stabilizers, tankyrase, and HSP90 inhibitors [273-275]. Based on the review of Ruden (2013), the most promising therapies/therapeutic compounds are the antisense oligonucleotide inhibitor GRN163L and immunotherapies that use dendritic cells (GRVAC1), hTERT peptide (GV1001) or cryptic peptides (Vx-001). These agents are currently being tested in phase I and II clinical trials in patients with various types of cancers. Promising results were obtained concerning the reduction of tumour growth inhibition, overall survival and disease stabilization, but 
combinatorial therapies appeared the most effective [273]. Concerning this therapeutic strategy, combining telomerase inhibition with pro-oxidant treatments also might result in accelerated telomere shortening, cancer cell senescence/death and tumour regression.

\subsubsection{System redox-related targets}

\section{Metabolic factors as therapeutic targets}

850

851

852

853

854

855

856

857

858

859

860

861

862

863

864

865

866

867

868

869

870

871

872

873

874

875

876

877

878

879

880

Cancer cells have an altered metabolism, (based on aerobic glycolysis) to sustain their demand for large quantities of proteins, lipids and nucleotides as well as for energy. They require NADH and NADPH for the correct functioning of their antioxidant systems. Targeting these reducing molecules, by targeting the metabolism, provides an indirect pro-oxidant therapeutic intervention [182]. This can be achieved by interfering with the glutamine metabolism, for example through inhibition of glutaminase 1 (GSL1), or with related pathways such as aspartate transaminase (GOT1), impairing GSH synthesis and inducing cell death [181]. Another interesting enzyme in the metabolic pathways of cancer cells is p53-inducible glycolysis and apoptosis regulator (TIGAR), the downstream target of p53. TIGAR regulates the redox balance in tumour cells by promoting NADPH production, generating reduced GSH to support cancer cell survival and tumour growth. A decrease in the number of tumours and a promotion of overall survival was shown in a TIGAR-deficient intestinal adenoma mouse model $[86,276]$.

The metabolism can also be targeted indirectly through alterations in the activity of redox-regulated upstream regulators of the metabolic pathways such as HIF, PI3K/Akt and AMP-activated protein kinase (AMPK). Metformin, an AMPK activator, has anticarcinogenic effects in both mouse models of breast cancers and in breast cancer patients. PI3K inhibitors reversed some of the metabolic phenotypes of cancer cells, resulting in tumour regression. Insulin-like growth factor receptors (IGFRs) regulate various signalling cascades, including the PI3K/Akt pathway, which makes them potential new targets for cancer therapy. However, it must be noted that these signalling pathways not only control the metabolism, they also act as upstream regulators of non-metabolic pathways. Studying the redox-regulated metabolic control and the precise roles of the upstream signalling factors during regeneration will provide a complete picture of their regulation of proliferation and cell death to optimize their function as specific anticarcinogenic targets.

\section{Inflammatory factors and the nervous system as therapeutic targets}

Although the immune and nervous system do not directly influence proliferation, differentiation or cell death, both systems are redox-regulated and have important roles during the carcinogenic process, therefore providing important targets for the development of anticancer drugs, which are discussed below.

Leukocyte recruitment and activation of both the innate and the adaptive immune system are directly related to tumour onset. Although not all the details are fully understood, various studies on long-term therapy with antiinflammatory drugs demonstrate their usefulness in inhibiting tumour progression and the development of malignancies. Analyses performed by Rothwell and colleagues revealed that daily aspirin users had a significantly lower risk of death from cancer (the 20-year risk of cancer death was reduced by $60 \%$ for gastrointestinal cancers and by $30 \%$ on average for other solid tumour cancers, including oesophageal, pancreatic, stomach, lung, brain 
and prostate cancers) in comparison to the group that did not receive a daily aspirin dose [277]. These analyses confirmed the results of earlier studies, which indicated that daily use of aspirin and other non-steroidal antiinflammatory drugs (NSAIDs) reduced the risk for colorectal tumour formation and reoccurrence of these polyps.

The immune system can also be targeted via the activation of granulocytes. These cells are important suppressors of tumour growth. Activated granulocytes produce ROS, thereby altering the redox environment of cancer cells, and generate other cytotoxic factors, such as proteases and membrane-proliferating agents. Granulocytes are recruited naturally into the tumour, but do not reach critical numbers to significantly affect the tumour via their cytolytic activities. Their presence results in tumour progression and metastasis because of the cross-talk between granulocytes and cancer cells. Augmenting the granulocyte activation and recruitment, which can be achieved by treatment with granulocyte colony-stimulating factor, increases specific antibody dependent cytotoxicity and decreases immunoresistance $[259,278]$.

Not only the immune system, but also the nervous system is involved in cancer development, as was indicated by multiple studies. A process named perineural invasion (PNI) improves tumour growth and metastasis through survival signals of the neurons and migration along the native nerve fibres $[279,280]$. The adrenergic fibres from the sympathetic nervous system were identified to be responsible for the promotion of tumour development and survival via $\beta 2$ - and $\beta 3$-adrenergic receptors, while cholinergic cells of the parasympathetic system promote tumour cell invasion and migration [279]. The 5-year disease-free survival rate is four-fold larger for patients with PNI-negative colorectal tumours in comparison to patients with PNI-positive tumours. The 5-year overall survival rate is $72 \%$ for PNI-negative tumours versus $25 \%$ for PNI-positive tumours [281]. The perineural system can be targeted by inhibition of the neurological functioning through intake of blockers that diminish tumour growth. Recent epidemiological data suggest that $\beta$-blocker intake is associated with improved survival of prostate cancer patients [279]. Targeting of the nerve growth factor (NGF) also inhibits tumour cell progression, survival and migration in breast cancer [282]. Although further research is necessary, these data already demonstrate the possibilities of drugs targeting both branches of the autonomic nervous system for cancer treatment.

The immune and nervous system are not only involved in carcinogenesis, they also come forward as important factors during the regeneration process. Their role, however, is adverse. The evolutionary improvement of the immune system in higher organisms, especially in vertebrates, resulted in the loss of regenerative capacities, while presence of neuronal cells is crucial for regeneration to proceed [283]. Acquiring more insights concerning their function in the regeneration process, and the role of the redox balance herein, in order to compare it with their function during the carcinogenic process, can deliver new insights in potential mechanisms that can be targeted to treat or even avoid tumour formation. In this way, not only new targets can be found, but also existing treatments can be improved. 


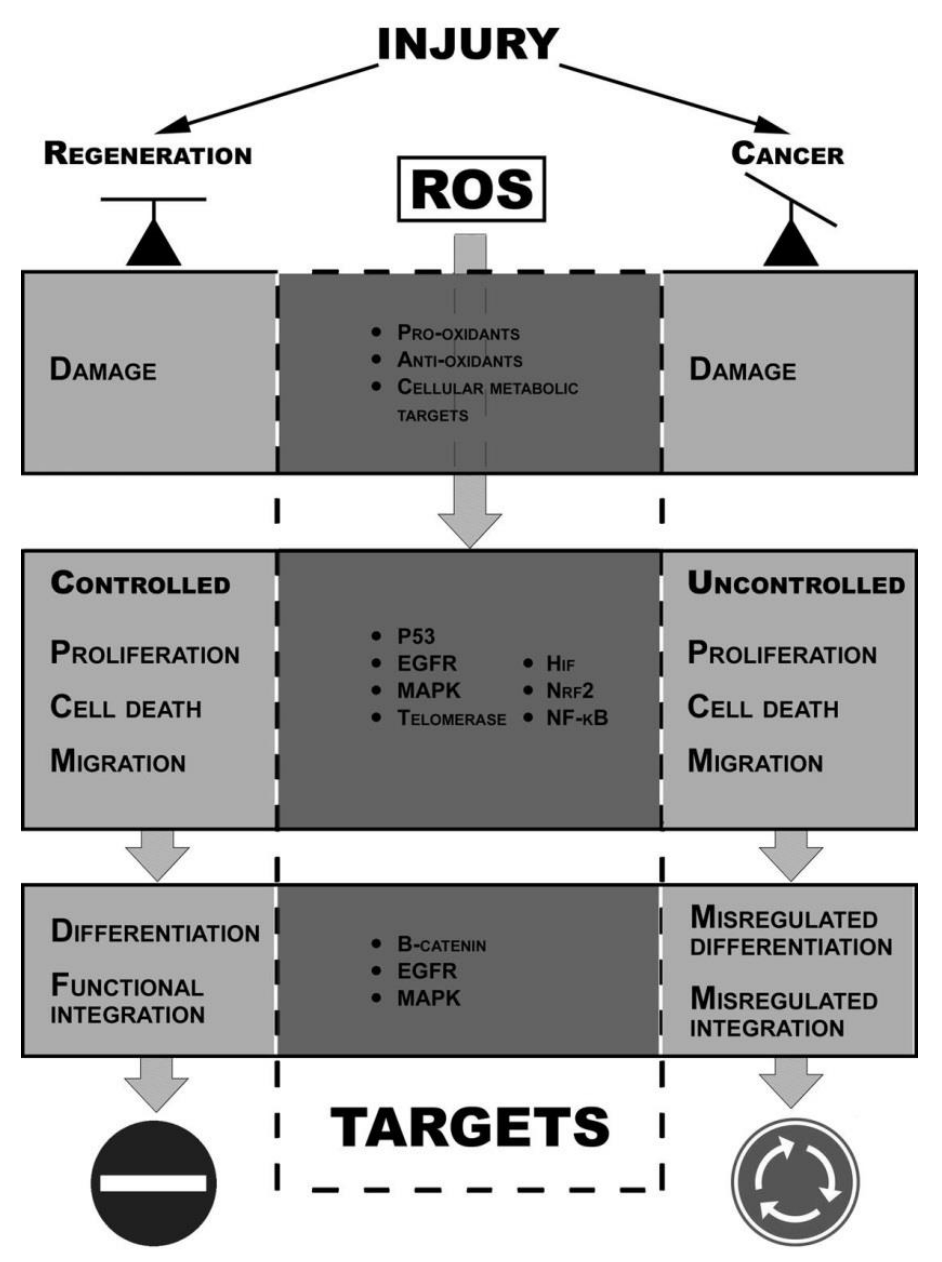

914 Figure 3: Redox-related anticarcinogenic targets in regenerative mechanisms. Regeneration and cancer share 915 many similarities, but have very opposite outcomes. The redox signature modulates the responses of cells to injury 916 in both processes. During regeneration, ROS signalling induces controlled cell proliferation, death and migration 917 for successful formation of the missing tissue. When growth and functional integration into the existing tissues are 918 completed, regeneration stops. However, during carcinogenesis the redox balance is disturbed and increased ROS 919 levels will cause DNA damage and loss of control over these cellular processes, leading to unwanted tumour 920 formation. Moreover, these tumour cells keep on dividing uncontrollably, ultimately resulting in death of the 921 organism. Since the redox signature controls regeneration and carcinogenesis, both at initiation and during later 922 stages, studying the role of the redox balance in controlling these mechanisms during regeneration, could provide interesting targets to control, overcome and even avoid cancer.

\subsubsection{Cancer stem cells as a therapeutic target}

Studying the process of regeneration is not only important in the abovementioned processes, it also delivers new insights into the underlying mechanisms of totipotency and pluripotency in stem cells, which again can be used in anticancer therapies, e.g. to target cancer stem cells. While conventional anticancer therapies predominantly attack the bulk tumour cell populations, cancer stem cells are often resistant to these therapies. As they seem to be the only fraction of tumour cells capable of initiating a new tumour, unmasking the factors that sustain cancer stem cell survival is necessary to develop more efficient therapies that reduce the risk of tumour relapse and metastasis 
[284-286]. One of the upstream regulators of the various phases of the cancer process and of stem cell quiescence,

both during cancer and regeneration, is the redox balance. Understanding its exact role in the activation/regulation of the specific stem cell processes offers opportunities towards new therapeutic strategies against cancer [284]. In the following sections, examples of existing and promising therapies that target the redox balance of cancer stem cells will be discussed.

Cancer stem cells often possess a higher resistance to radio- or chemotherapy as a result of higher defence potentials against ROS. Adhesion molecules and stem cell markers, such as CD44 and its alternative mRNA splicing variant CD44v, which stimulate the intracellular GSH levels, are examples of protection mechanisms of cancer stem cells against high environmental ROS levels (as explained in section 2.3.2) [287]. An upregulation of CD44 in cancer stem cells is believed to be responsible for the incurability of glioblastoma multiforme, the most aggressive brain tumour. Therapies that target CD44, through RNAi or via administration of a monoclonal antibody, are able to disturb the ROS defence of cancer stem cells and are potential therapeutic targets to kill cancer stem cells in various tumours [1, 286, 287].

Another defence mechanism of cancer stem cells is the expression of multidrug resistance $\mathrm{ABC}$ transporters that pump redox-altering drugs out of the cell. The chemoresistance mediator ABCB5 positively correlates with neoplastic progression in human melanoma patients and is preferentially expressed by melanomas with high in vivo tumorigenic capacity and of metastatic tumour origin. Administration of an anti-ABCB5 antibody substantially inhibits tumour formation and growth in melanoma mice and overcomes resistance to the $\mathrm{H}_{2} \mathrm{O}_{2}$ generating, chemotherapeutic agent doxorubicin [286].

Cancer stem cells also protect themselves against redox-altering chemotherapies and targeted therapies by maintaining a quiescent state. The induction of differentiation in quiescent cancer stem cells is therefore a promising approach to eliminate cancer stem cells. This can be achieved among others by administration of Notch pathway inhibitors, which were shown to deplete medulloblastoma stem-like cells or by enforced expression of miRNAs which induces differentiation of breast cancer stem cells and inhibits their tumour-forming ability in mice. Doxorubicin and cyclophosphamide therapy in combination with an epigenetic therapy with the demethylating agent hydralazine and the histone deacetylase inhibitor magnesium valproate also induces cancer stem cell differentiation and improves clinical outcome of breast cancer patients [286]. Arsenic trioxide is thought to eliminate cancer stem cells through degradation of PML, a tumour suppressor gene involved in the chromosomal translocation of promyelocytic leukaemia as well as an important factor in maintaining the quiescent state of CML cancer stem cells, and through increasing ROS levels [1].

Finally, the preferential activation of the DNA damage checkpoint response and increased DNA repair capacity which can diminish therapy-induced ROS damage is thought to increase the radioresistance of cancer stem cells. An inhibition of the Chk1 and Chk2 checkpoint kinases for example reversed the radioresistance of CD133+ glioma cancer stem cells [286].

Not only stem cells but also the tissue microenvironment, consisting of resident and infiltrating host cells and components of the extracellular matrix, play an essential role in regeneration, cancer development and the 
modulation of cell responses to cancer treatments [95, 287]. The niche of cancer stem cells controls their selfrenewal, proliferation, differentiation and apoptosis and protects them against genotoxic insults. In addition, it can generate cancer stem cells through induction of stem-like features in more differentiated tumour cells by reactivating the Wnt pathway. The niche of cancer stem cells is also involved in metastasis by inducing EMT and by formation of a premetastatic niche for secondary tumours. The niche and its mediators are therefore also used as targets for anticancer therapy [95, 287]. An example are the anti-MET antibodies that inhibit hepatocyte growth factor, produced by the microenvironment, to bind to the tyrosine kinase receptor MET, and in this way inhibit colon cancer growth [285].

\section{Conclusion}

ROS signalling is involved in multiple cellular processes including cell proliferation, cell death, cell differentiation and cell migration through which they regulate correct physiological responses and tissue regeneration. A controlled redox balance is also crucial to maintain self-renewal capacities and to regulate stem cell fate. Disturbances in this balance, induced by either endogenous or external factors, initiate many pathological conditions including neurodegeneration, immunity disorders and cancer. In tumours, ROS are not only important for the induction of DNA damage in proto-oncogenes, oncogenes or tumour suppressor genes, disturbances in the redox signature also support cancer cell survival through altering signalling pathways, affecting the microenvironment and promoting migration and metastasis. Therefore, cancer cells and cancer stem cells regulate ROS levels dynamically to enable this oxidative damage and malignant transformation while avoiding cell death. Pro-oxidative mechanisms include upregulation of ROS-producing enzymes via tumour suppressor genes and oncogenes, and stimulation of the metabolism. The activation of redox-sensitive transcription factors that upregulate antioxidant ROS scavenging enzymes and promote metastasis are strategies of cancer cells to prevent ROS levels to reach a cell death threshold. Many redox-based anticarcinogenic therapies that target the differential redox state of cancer cells in comparison with non-cancer cells are currently being developed and applied. Although they give positive outcomes concerning tumour regression and prevention of metastasis, these therapies have disadvantages such as a lack of specificity and induction of drug resistance. Especially cancer stem cells, which possess enhanced protection mechanisms against ROS-induced stress, are less vulnerable to redox-based anticarcinogenic therapies, thereby increasing the chance of tumour relapse. To tackle these shortcomings of direct redox-related therapies, better insights concerning the involvement of the redox balance as a regulator in cancerrelated processes should be obtained. In this regard, the regeneration process, which is a normal physiological process in diverse animals and/or life stages, offers a unique context to study the importance of ROS signalling in controlling cell proliferation, cell death and cell migration. Various genes and mechanisms that are essential in the establishment of successful regeneration have been shown to be disturbed in carcinogenesis, many of which are redox-controlled. These genes and mechanisms offer interesting indirect redox-related targets to fine-tune existing therapies. For example, therapeutics targeting tumour suppressor genes like p53 or MAPK cascades are promising for the treatment of cancer. In addition, new insights in behaviour and adaptive responses of stem cells to changing environments as well as during unsuccessful regeneration could reveal potential therapeutic targets against cancer stem cells. 
Redox-related direct and indirect mechanisms are not only interesting in cancer treatment, but also in cancer prevention. Epidemiological studies that linked high consumptions of antioxidant-rich fruits and vegetables with a better health, have led to the assumption that dietary intake of antioxidants, such as curcumin, reduces ROS and ROS-associated diseases. Although people with certain genetic polymorphisms in antioxidant genes might benefit from these supplements, some caution must be exercised. An improvident use of antioxidants has been associated with a decrease in general health and even an elevated risk of mortality. The potential impeding effects of antioxidants with treatment success of radio- and chemotherapy, both depending on ROS to induce cytotoxicity in tumours, has also been a subject of discussion in the medical community.

In summary, redox-related therapies are interesting and active areas of on-going cancer research. However, more resources should be invested in studies that explore the basic defaults that occur in the initiation of cancer transformation. Since high regenerative capacities are associated with tumour repressing abilities, unravelling regeneration processes that suppress malignant transformation provide opportunities to overcome, treat and even avoid cancer.

\section{Acknowledgements}

The authors thank Jan-Pieter Ploem for helping to generate the figures and Dr Michelle Plusquin for her suggestions to the article.

This work was supported by the Bijzonder OnderzoeksFonds of Hasselt University (BOF08G01) and Hasselt University tUL-impulsfinanciering (project toxicology). The work of An-Sofie Stevens was financed by a PhD grant for An-Sofie Stevens from IWT (Agentschap voor Innovatie door Wetenschap en Technologie) (no. 101442). Maxime Willems was funded by an OZM grant by IWT (no. 100631). 


\section{$\underline{\text { References }}$}

1042 [1] Kobayashi $\mathrm{Cl}$, Suda T. Regulation of reactive oxygen species in stem cells and cancer stem cells. J

1043 Cell Physiol 2012; 227(2): 421-30.

1044 [2] Finkel T, Holbrook NJ. Oxidants, oxidative stress and the biology of ageing. Nature 2000; 408(6809): 239-47.

[3] Dröge W. Free radicals in the physiological control of cell function. Physiol Rev 2002; 82(1): 47-95. [4] Buonocore G, Perrone S, Tataranno ML. Oxygen toxicity: chemistry and biology of reactive oxygen species. Semin Fetal Neonatal Med 2010; 15(4): 186-90.

[5] Kanta J. The role of hydrogen peroxide and other reactive oxygen species in wound healing. Acta Medica (Hradec Kralove) 2011; 54(3): 97-101.

[6] Brieger K, Schiavone S, Miller FJ, Jr., Krause KH. Reactive oxygen species: from health to disease. Swiss Med Wkly 2012; 142: w13659.

[7] Covarrubias L, Hernández-García D, Schnabel D, Salas-Vidal E, Castro-Obregón S. Function of reactive oxygen species during animal development: passive or active? Dev Biol 2008; 320(1): 1-11.

[8] Jiang F, Zhang Y, Dusting GJ. NADPH oxidase-mediated redox signaling: roles in cellular stress response, stress tolerance, and tissue repair. Pharmacol Rev 2011; 63(1): 218-42.

[9] Fleury C, Mignotte B, Vayssiere JL. Mitochondrial reactive oxygen species in cell death signaling. Biochimie 2002; 84(2-3): 131-41.

[10] Murphy MP. How mitochondria produce reactive oxygen species. Biochem J 2009; 417(1): 1-13.

[11] Bienert GP, Moller AL, Kristiansen KA, et al. Specific aquaporins facilitate the diffusion of hydrogen peroxide across membranes. J Biol Chem 2007; 282(2): 1183-92.

[12] Balaban RS, Nemoto S, Finkel T. Mitochondria, oxidants, and aging. Cell 2005; 120(4): 483-95.

[13] Gupta RK, Patel AK, Shah N, et al. Oxidative Stress and Antioxidants in Disease and Cancer: A. Asian Pac J Cancer Prev 2014; 15(11): 4405-9.

[14] Willcox JK, Ash SL, Catignani GL. Antioxidants and prevention of chronic disease. Crit Rev Food Sci Nutr 2004; 44(4): 275-95.

[15] Halliwell B, Gutteridge J. Cellular responses to oxidative stress: adaptation, damage, repair, senescence and death. New York: Oxford University; 2007.

[16] Copple IM, Goldring CE, Jenkins RE, et al. The hepatotoxic metabolite of acetaminophen directly activates the Keap1-Nrf2 cell defense system. Hepatology 2008; 48(4): 1292-301.

[17] Kaspar JW, Niture SK, Jaiswal AK. Nrf2:INrf2 (Keap1) signaling in oxidative stress. Free Radic Biol Med 2009; 47(9): 1304-9.

[18] Nguyen T, Nioi P, Pickett CB. The Nrf2-antioxidant response element signaling pathway and its activation by oxidative stress. J Biol Chem 2009; 284(20): 13291-5.

[19] Tell G, Quadrifoglio F, Tiribelli C, Kelley MR. The many functions of APE1/Ref-1: not only a DNA repair enzyme. Antioxid Redox Signal 2009; 11(3): 601-20.

[20] Bhakat KK, Mantha AK, Mitra S. Transcriptional regulatory functions of mammalian APendonuclease (APE1/Ref-1), an essential multifunctional protein. Antioxid Redox Signal 2009; 11(3): 621-38.

[21] Liu B, Chen Y, St Clair DK. ROS and p53: a versatile partnership. Free Radical Biology and Medicine 2008; 44(8): 1529-35.

[22] Kops GJ, Dansen TB, Polderman PE, et al. Forkhead transcription factor FOXO3a protects quiescent cells from oxidative stress. Nature 2002; 419(6904): 316-21.

[23] Alexander A, Kim J, Walker CL. ATM engages the TSC2/mTORC1 signaling node to regulate autophagy. Autophagy 2010; 6(5): 672-3.

[24] Cosentino C, Grieco D, Costanzo V. ATM activates the pentose phosphate pathway promoting antioxidant defence and DNA repair. EMBO J 2011; 30(3): 546-55.

[25] Ditch S, Paull TT. The ATM protein kinase and cellular redox signaling: beyond the DNA damage response. Trends Biochem Sci 2012; 37(1): 15-22.

[26] Bubici C, Papa S, Pham CG, Zazzeroni F, Franzoso G. The NF-kappaB-mediated control of ROS and JNK signaling. Histol Histopathol 2006; 21(1): 69-80. 
[27] Janssen-Heininger $\mathrm{YM}$, Mossman BT, Heintz NH, et al. Redox-based regulation of signal transduction: principles, pitfalls, and promises. Free Radic Biol Med 2008; 45(1): 1-17.

[28] Winterbourn CC, Hampton MB. Thiol chemistry and specificity in redox signaling. Free Radical Biol Med 2008; 45(5): 549-61.

[29] Zhang W, Liu HT. MAPK signal pathways in the regulation of cell proliferation in mammalian cells.

[30] Chang L, Karin M. Mammalian MAP kinase signalling cascades. Nature 2001; 410(6824): 37-40.

[31] Wagner EF, Nebreda AR. Signal integration by JNK and p38 MAPK pathways in cancer development. Nat Rev Cancer 2009; 9(8): 537-49.

[32] Alfadda AA, Sallam RM. Reactive oxygen species in health and disease. J Biomed Biotechnol 2012; 2012: 936486.

[33] Klaunig JE, Kamendulis LM, Hocevar BA. Oxidative stress and oxidative damage in carcinogenesis. Toxicol Pathol 2010; 38(1): 96-109.

[34] Waris G, Ahsan H. Reactive oxygen species: role in the development of cancer and various chronic conditions. J Carcinog 2006; 5: 14.

[35] Bridge G, Rashid S, Martin SA. DNA mismatch repair and oxidative DNA damage: implications for cancer biology and treatment. Cancers (Basel) 2014; 6(3): 1597-614.

[36] Hernandez-Garcia D, Castro-Obregon S, Gomez-Lopez S, Valencia C, Covarrubias L. Cell death activation during cavitation of embryoid bodies is mediated by hydrogen peroxide. Exp Cell Res 2008; 314(10): 2090-9.

[37] Dewaele M, Maes H, Agostinis P. ROS-mediated mechanisms of autophagy stimulation and their relevance in cancer therapy. Autophagy 2010; 6(7): 838-54.

[38] Scherz-Shouval R, Shvets E, Fass E, Shorer H, Gil L, Elazar Z. Reactive oxygen species are essential for autophagy and specifically regulate the activity of Atg4. EMBO J 2007; 26(7): 1749-60.

[39] Kawanishi S, Oikawa S. Mechanism of telomere shortening by oxidative stress. Ann N Y Acad Sci 2004; 1019: 278-84.

[40] Petersen S, Saretzki G, von Zglinicki T. Preferential accumulation of single-stranded regions in telomeres of human fibroblasts. Exp Cell Res 1998; 239(1): 152-60.

[41] Indran IR, Hande MP, Pervaiz S. hTERT overexpression alleviates intracellular ROS production, improves mitochondrial function, and inhibits ROS-mediated apoptosis in cancer cells. Cancer Res 2011; 71(1): 266-76.

[42] Sahin E, Depinho RA. Linking functional decline of telomeres, mitochondria and stem cells during ageing. Nature 2010; 464(7288): 520-8.

[43] Chen L, Liu L, Yin J, Luo Y, Huang S. Hydrogen peroxide-induced neuronal apoptosis is associated with inhibition of protein phosphatase $2 A$ and 5 , leading to activation of MAPK pathway. Int J Biochem Cell Biol 2009; 41(6): 1284-95.

[44] Funato $Y$, Michiue $T$, Asashima M, Miki $H$. The thioredoxin-related redox-regulating protein nucleoredoxin inhibits Wnt-beta-catenin signalling through dishevelled. Nat Cell Biol 2006; 8(5): 5018.

[45] Korswagen HC. Regulation of the Wnt/beta-catenin pathway by redox signaling. Dev Cell 2006; 10(6): 687-8.

[46] Kajla S, Mondol AS, Nagasawa A, et al. A crucial role for Nox 1 in redox-dependent regulation of Wnt-beta-catenin signaling. FASEB J 2012; 26(5): 2049-59.

[47] Wen JW, Hwang JT, Kelly GM. Reactive oxygen species and Wnt signalling crosstalk patterns mouse extraembryonic endoderm. Cell Signal 2012; 24(12): 2337-48.

[48] Sandieson L, Hwang JT, Kelly GM. Redox regulation of canonical Wnt signaling affects extraembryonic endoderm formation. Stem Cells Dev 2014; 23(10): 1037-49.

[49] Ushio-Fukai M, Rehman J. Redox and metabolic regulation of stem/progenitor cells and their niche. Antioxid Redox Signal 2014; 21(11): 1587-90.

[50] Finkel T. Signal transduction by mitochondrial oxidants. J Biol Chem 2012; 287(7): 4434-40.

[51] Wang K, Zhang T, Dong Q, Nice EC, Huang C, Wei Y. Redox homeostasis: the linchpin in stem cell self-renewal and differentiation. Cell Death Dis 2013; 4: e537. 
[52] Nair AR, Degheselle O, Smeets K, Van Kerkhove E, Cuypers A. Cadmium-Induced Pathologies: Where Is the Oxidative Balance Lost (or Not)? Int J Mol Sci 2013; 14(3): 6116-43.

[53] Fehrer C, Brunauer R, Laschober G, et al. Reduced oxygen tension attenuates differentiation capacity of human mesenchymal stem cells and prolongs their lifespan. Aging Cell 2007; 6(6): 745-57. [54] Sanchez Alvarado A. Cellular hyperproliferation and cancer as evolutionary variables. Curr Biol 2012; 22(17): R772-8.

[55] Sudhakar A. History of Cancer, Ancient and Modern Treatment Methods. J Cancer Sci Ther 2009; 1(2): 1-4.

[56] Hanahan D, Weinberg RA. Hallmarks of cancer: the next generation. Cell 2011; 144(5): 646-74.

[57] Reuter S, Gupta SC, Chaturvedi MM, Aggarwal BB. Oxidative stress, inflammation, and cancer: how are they linked? Free Radic Biol Med 2010; 49(11): 1603-16.

[58] Sedelnikova OA, Redon CE, Dickey JS, Nakamura AJ, Georgakilas AG, Bonner WM. Role of oxidatively induced DNA lesions in human pathogenesis. Mutation Research/Reviews in Mutation Research 2010; 704(1-3): 152-9.

[59] Goodsell DS. The molecular perspective: the ras oncogene. Oncologist 1999; 4(3): 263-4.

[60] Ozaki T, Nakagawara A. Role of p53 in Cell Death and Human Cancers. Cancers (Basel) 2011; 3(1): 994-1013.

[61] Pomerantz JH, Blau HM. Tumor suppressors: enhancers or suppressors of regeneration? Development 2013; 140(12): 2502-12.

[62] Rivlin N, Brosh R, Oren M, Rotter V. Mutations in the p53 Tumor Suppressor Gene: Important Milestones at the Various Steps of Tumorigenesis. Genes Cancer 2011; 2(4): 466-74.

[63] Olivier M, Hollstein M, Hainaut P. TP53 Mutations in Human Cancers: Origins, Consequences, and Clinical Use. Cold Spring Harb Perspect Biol 2010; 2(1).

[64] Raatikainen S, Aaltomaa S, Kärjä V, Soini Y. Increased nuclear factor erythroid 2-related factor 2 expression predicts worse prognosis of prostate cancer patients treated with radical prostatectomy. Hum Pathol; (0).

[65] Wang W, He YF, Sun QK, et al. Hypoxia-inducible factor 1alpha in breast cancer prognosis. Clin Chim Acta 2014; 428: 32-7.

[66] Huang $M$, Chen $Q$, Xiao J, et al. Overexpression of hypoxia-inducible factor-1alpha is a predictor of poor prognosis in cervical cancer: a clinicopathologic study and a meta-analysis. Int J Gynecol Cancer 2014; 24(6): 1054-64.

[67] Ye LY, Zhang Q, Bai XL, Pankaj P, Hu QD, Liang TB. Hypoxia-inducible factor 1alpha expression and its clinical significance in pancreatic cancer: A meta-analysis. Pancreatology 2014; 14(5): 391-7.

[68] Liou GY, Storz P. Reactive oxygen species in cancer. Free Radic Res 2010; 44(5): 479-96.

[69] Fiaschi T, Chiarugi P. Oxidative stress, tumor microenvironment, and metabolic reprogramming: a diabolic liaison. Int J Cell Biol 2012; 2012: 762825.

[70] Pani G, Galeotti T, Chiarugi P. Metastasis: cancer cell's escape from oxidative stress. Cancer and Metastasis Reviews 2010; 29(2): 351-78.

[71] Bell EL, Klimova TA, Eisenbart J, Schumacker PT, Chandel NS. Mitochondrial reactive oxygen species trigger hypoxia-inducible factor-dependent extension of the replicative life span during hypoxia. Mol Cell Biol 2007; 27(16): 5737-45.

[72] Xia C, Meng Q, Liu LZ, Rojanasakul Y, Wang XR, Jiang BH. Reactive oxygen species regulate angiogenesis and tumor growth through vascular endothelial growth factor. Cancer Res 2007; 67(22): 10823-30.

[73] Liu C, Huang $\mathrm{H}$, Wang $\mathrm{C}$, Kong $\mathrm{Y}$, Zhang $\mathrm{H}$, Zhang $\mathrm{H}$. Association between OGG1 gene single nucleotide polymorphisms and risk of pancreatic cancer in Chinese. Med Oncol 2014; 31(7): 40.

[74] Diaz B, Shani G, Pass I, Anderson D, Quintavalle M, Courtneidge SA. Tks5-dependent, noxmediated generation of reactive oxygen species is necessary for invadopodia formation. Sci Signal 2009; 2(88): ra53.

[75] Costa A, Scholer-Dahirel A, Mechta-Grigoriou F. The role of reactive oxygen species and metabolism on cancer cells and their microenvironment. Semin Cancer Biol 2014; 25: 23-32. 
[76] Roessner A, Kuester D, Malfertheiner P, Schneider-Stock R. Oxidative stress in ulcerative colitisassociated carcinogenesis. Pathology - Research and Practice 2008; 204(7): 511-24.

[77] Warburg O. On the origin of cancer cells. Science 1956; 123(3191): 309-14.

[78] Pavlides S, Whitaker-Menezes D, Castello-Cros R, et al. The reverse Warburg effect: aerobic glycolysis in cancer associated fibroblasts and the tumor stroma. Cell Cycle 2009; 8(23): 3984-4001.

[79] Martinez-Outschoorn UE, Balliet RM, Rivadeneira DB, et al. Oxidative stress in cancer associated fibroblasts drives tumor-stroma co-evolution: A new paradigm for understanding tumor metabolism, the field effect and genomic instability in cancer cells. Cell Cycle 2010; 9(16): 3256-76.

[80] Martinez-Outschoorn UE, Trimmer C, Lin Z, et al. Autophagy in cancer associated fibroblasts promotes tumor cell survival: Role of hypoxia, HIF1 induction and NFkappaB activation in the tumor stromal microenvironment. Cell Cycle 2010; 9(17): 3515-33.

[81] Pavlides S, Vera I, Gandara R, et al. Warburg meets autophagy: cancer-associated fibroblasts accelerate tumor growth and metastasis via oxidative stress, mitophagy, and aerobic glycolysis. Antioxid Redox Signal 2012; 16(11): 1264-84.

[82] Yang ZJ, Chee CE, Huang S, Sinicrope FA. The role of autophagy in cancer: therapeutic implications. Mol Cancer Ther 2011; 10(9): 1533-41.

[83] Donatelli SS, Zhou JM, Gilvary DL, et al. TGF-beta-inducible microRNA-183 silences tumorassociated natural killer cells. Proc Natl Acad Sci U S A 2014; 111(11): 4203-8.

[84] Barcellos-Hoff MH, Dix TA. Redox-mediated activation of latent transforming growth factor-beta 1. Mol Endocrinol 1996; 10(9): 1077-83.

[85] Gupta SC, Hevia D, Patchva S, Park B, Koh W, Aggarwal BB. Upsides and Downsides of Reactive Oxygen Species for Cancer: The Roles of Reactive Oxygen Species in Tumorigenesis, Prevention, and Therapy. Antioxid Redox Signal 2011; 16(11): 1295-322.

[86] Cheung EC, Athineos D, Lee $P$, et al. TIGAR is required for efficient intestinal regeneration and tumorigenesis. Dev Cell 2013; 25(5): 463-77.

[87] Yang W, Zou L, Huang C, Lei Y. Redox Regulation of Cancer Metastasis: Molecular Signaling and Therapeutic Opportunities. Drug Dev Res 2014; 75(5): 331-41.

[88] Ushio-Fukai M, Nakamura Y. Reactive oxygen species and angiogenesis: NADPH oxidase as target for cancer therapy. Cancer Lett 2008; 266(1): 37-52.

[89] Khandrika L, Kumar B, Koul S, Maroni P, Koul HK. Oxidative stress in prostate cancer. Cancer Lett 2009; 282(2): 125-36.

[90] Clerkin JS, Naughton R, Quiney C, Cotter TG. Mechanisms of ROS modulated cell survival during carcinogenesis. Cancer Lett 2008; 266(1): 30-6.

[91] Vafa O, Wade M, Kern S, et al. c-Myc can induce DNA damage, increase reactive oxygen species, and mitigate p53 function: a mechanism for oncogene-induced genetic instability. Mol Cell 2002; 9(5): 1031-44.

[92] Shinohara $M$, Shang $\mathrm{W}-\mathrm{H}$, Kubodera $\mathrm{M}$, et al. Nox1 Redox Signaling Mediates Oncogenic Rasinduced Disruption of Stress Fibers and Focal Adhesions by Down-regulating Rho. J Biol Chem 2007; 282(24): 17640-8.

[93] Kopnin PB, Agapova LS, Kopnin BP, Chumakov PM. Repression of sestrin family genes contributes to oncogenic Ras-induced reactive oxygen species up-regulation and genetic instability. Cancer Res 2007; 67(10): 4671-8.

[94] Sablina AA, Budanov AV, Ilyinskaya GV, Agapova LS, Kravchenko JE, Chumakov PM. The antioxidant function of the p53 tumor suppressor. Nat Med 2005; 11(12): 1306-13.

[95] Trachootham D, Chen G, Zhang W, et al. Loss of p53 in stromal fibroblasts promotes epithelial cell invasion through redox-mediated ICAM1 signal. Free Radical Biol Med 2013; 58: 1-13.

[96] Greaves LC, Reeve AK, Taylor RW, Turnbull DM. Mitochondrial DNA and disease. The Journal of Pathology 2012; 226(2): 274-86.

[97] Piruat JI, Millan-Ucles A. Genetically modeled mice with mutations in mitochondrial metabolic enzymes for the study of cancer. Front Oncol 2014; 4: 200.

[98] Jiao F, Liu Y, Qu Y, et al. Studies on anti-tumor and antimetastatic activities of fullerenol in a mouse breast cancer model. Carbon 2010; 48(8): 2231-43. 
[99] Ilmer M, Vykoukal J, Recio Boiles A, Coleman M, Alt E. Two sides of the same coin: stem cells in cancer and regenerative medicine. FASEB J 2014; 28(7): 2748-61.

[100] Heddleston JM, Li Z, Lathia JD, Bao S, Hjelmeland AB, Rich JN. Hypoxia inducible factors in cancer stem cells. Br J Cancer 2010; 102(5): 789-95.

[101] Cairns RA, Harris IS, Mak TW. Regulation of cancer cell metabolism. Nat Rev Cancer 2011; 11(2): 85-95.

[102] Hileman EO, Liu J, Albitar M, Keating MJ, Huang P. Intrinsic oxidative stress in cancer cells: a biochemical basis for therapeutic selectivity. Cancer Chemother Pharmacol 2004; 53(3): 209-19.

[103] Carew JS, Zhou Y, Albitar M, Carew JD, Keating MJ, Huang P. Mitochondrial DNA mutations in primary leukemia cells after chemotherapy: clinical significance and therapeutic implications. Leukemia 2003; 17(8): 1437-47.

[104] Acharya A, Das I, Chandhok D, Saha T. Redox regulation in cancer: a double-edged sword with therapeutic potential. Oxid Med Cell Longev 2010; 3(1): 23-34.

[105] Cui X. Reactive Oxygen Species: The Achilles' Heel of Cancer Cells? Antioxidants \& Redox Signaling 2012; 16(11): 1212-4.

[106] Nagano O, Okazaki S, Saya H. Redox regulation in stem-like cancer cells by CD44 variant isoforms. Oncogene 2013; 32(44): 5191-8.

[107] Ishimoto T, Nagano O, Yae T, et al. CD44 Variant Regulates Redox Status in Cancer Cells by Stabilizing the XCT Subunit of System xc- and Thereby Promotes Tumor Growth. Cancer Cell 2011; 19(3): 387-400.

[108] Oviedo NJ, Beane WS. Regeneration: The origin of cancer or a possible cure? Semin Cell Dev Biol 2009; 20(5): 557-64.

[109] Seifert AW, Voss SR. Revisiting the relationship between regenerative ability and aging. BMC Biol 2013; $11: 2$.

[110] Galliot B. Injury-induced asymmetric cell death as a driving force for head regeneration in Hydra. Dev Genes Evol 2013; 223(1-2): 39-52.

[111] Endo T, Bryant SV, Gardiner DM. A stepwise model system for limb regeneration. Dev Biol 2004; 270(1): 135-45.

[112] Mathew LK, Sengupta S, Kawakami $A$, et al. Unraveling tissue regeneration pathways using chemical genetics. J Biol Chem 2007; 282(48): 35202-10.

[113] Brockes JP, Kumar A. Comparative aspects of animal regeneration. Annu Rev Cell Dev Biol 2008; 24: 525-49.

[114] Kennedy KA, Sandiford SD, Skerjanc IS, Li SS. Reactive oxygen species and the neuronal fate. Cell Mol Life Sci 2012; 69(2): 215-21.

[115] Bedard K, Krause KH. The NOX family of ROS-generating NADPH oxidases: physiology and pathophysiology. Physiol Rev 2007; 87(1): 245-313.

[116] Suzukawa K, Miura K, Mitsushita J, et al. Nerve growth factor-induced neuronal differentiation requires generation of Rac1-regulated reactive oxygen species. J Biol Chem 2000; 275(18): 13175-8.

[117] Kennedy KA, Ostrakhovitch EA, Sandiford SD, et al. Mammalian numb-interacting protein 1/dual oxidase maturation factor 1 directs neuronal fate in stem cells. J Biol Chem 2010; 285(23): 17974-85. [118] Min JY, Park MH, Park MK, et al. Staurosporin induces neurite outgrowth through ROS generation in HN33 hippocampal cell lines. J Neural Transm Gen Sect 2006; 113(11): 1821-6.

[119] Gotenstein JR, Swale RE, Fukuda T, et al. The C. elegans peroxidasin PXN-2 is essential for embryonic morphogenesis and inhibits adult axon regeneration. Development 2010; 137(21): 360313.

[120] Rieger S, Sagasti A. Hydrogen peroxide promotes injury-induced peripheral sensory axon regeneration in the zebrafish skin. PLoS Biol 2011; 9(5): e1000621.

[121] Gauron C, Rampon C, Bouzaffour M, et al. Sustained production of ROS triggers compensatory proliferation and is required for regeneration to proceed. Sci Rep 2013; 3: 2084.

[122] Love NR, Chen Y, Ishibashi S, et al. Amputation-induced reactive oxygen species are required for successful Xenopus tadpole tail regeneration. Nat Cell Biol 2013; 15(2): 222-8. 
[123] Niethammer P, Grabher C, Look AT, Mitchison TJ. A tissue-scale gradient of hydrogen peroxide mediates rapid wound detection in zebrafish. Nature 2009; 459(7249): 996-9.

[124] Adell T, Cebrià F, Saló E. Gradients in Planarian Regeneration and Homeostasis. Cold Spring Harb Perspect Biol 2010; 2(1).

[125] Nejak-Bowen KN, Monga SP. Beta-catenin signaling, liver regeneration and hepatocellular cancer: sorting the good from the bad. Semin Cancer Biol 2011; 21(1): 44-58.

[126] Tasaki J, Shibata N, Sakurai T, Agata K, Umesono Y. Role of c-Jun N-terminal kinase activation in blastema formation during planarian regeneration. Dev Growth Differ 2011; 53(3): 389-400.

[127] Tasaki J, Shibata N, Nishimura O, et al. ERK signaling controls blastema cell differentiation during planarian regeneration. Development 2011; 138(12): 2417-27.

[128] Umesono Y, Tasaki J, Nishimura Y, et al. The molecular logic for planarian regeneration along the anterior-posterior axis. Nature 2013; 500(7460): 73-6.

[129] Agata K, Tasaki J, Nakajima E, Umesono Y. Recent identification of an ERK signal gradient governing planarian regeneration. Zoology (Jena) 2014; 117(3): 161-2.

[130] King RS, Newmark PA. The cell biology of regeneration. J Cell Biol 2012; 196(5): 553-62.

[131] Harsum S, Clarke JD, Martin P. A reciprocal relationship between cutaneous nerves and repairing skin wounds in the developing chick embryo. Dev Biol 2001; 238(1): 27-39.

[132] Cebria F, Newmark PA. Morphogenesis defects are associated with abnormal nervous system regeneration following roboA RNAi in planarians. Development 2007; 134(5): 833-7.

[133] Oviedo N, Morokuma J, Walentek P, et al. Long-range neural and gap junction protein-mediated cues control polarity during planarian regeneration. Dev Biol 2010; 339: 188 - 99.

[134] Nix P, Hisamoto N, Matsumoto K, Bastiani M. Axon regeneration requires coordinate activation of p38 and JNK MAPK pathways. Proc Natl Acad Sci U S A 2011; 108(26): 10738-43.

[135] Hammarlund $M$, Nix $P$, Hauth L, Jorgensen EM, Bastiani M. Axon regeneration requires a conserved MAP kinase pathway. Science 2009; 323(5915): 802-6.

[136] Ling S, Chang X, Schultz L, et al. An EGFR-ERK-SOX9 Signaling Cascade Links Urothelial Development and Regeneration to Cancer. Cancer Res 2011; 71(11): 3812-21.

[137] Levin M. Morphogenetic fields in embryogenesis, regeneration, and cancer: non-local control of complex patterning. BioSyst 2012; 109(3): 243-61.

[138] Riss J, Khanna C, Koo S, et al. Cancers as wounds that do not heal: differences and similarities between renal regeneration/repair and renal cell carcinoma. Cancer Res 2006; 66(14): 7216-24.

[139] Tögel F, Westenfelder C. The role of multipotent marrow stromal cells (MSCs) in tissue regeneration. Organogenesis 2011; 7(2): 96-100.

[140] Bergfeld SA, DeClerck YA. Bone marrow-derived mesenchymal stem cells and the tumor microenvironment. Cancer and Metastasis Reviews 2010; 29(2): 249-61.

[141] Jiang Z, Zacksenhaus E, Gallie BL, Phillips RA. The retinoblastoma gene family is differentially expressed during embryogenesis. Oncogene 1997; 14(15): 1789-97.

[142] Clarke AR, Maandag ER, van Roon M, et al. Requirement for a functional Rb-1 gene in murine development. Nature 1992; 359(6393): 328-30.

[143] Yun MH, Gates PB, Brockes JP. Regulation of p53 is critical for vertebrate limb regeneration. Proceedings of the National Academy of Sciences 2013; 110(43): 17392-7.

[144] Wells BS, Johnston LA. Maintenance of imaginal disc plasticity and regenerative potential in Drosophila by p53. Dev Biol 2012; 361(2): 263-76.

[145] Di Giovanni S, Rathore K. p53-dependent pathways in neurite outgrowth and axonal regeneration. Cell and Tissue Research 2012; 349(1): 87-95.

[146] Kurinna S, Stratton SA, Coban Z, et al. p53 regulates a mitotic transcription program and determines ploidy in normal mouse liver. Hepatology 2013; 57(5): 2004-13.

[147] Hollander MC, Blumenthal GM, Dennis PA. PTEN loss in the continuum of common cancers, rare syndromes and mouse models. Nat Rev Cancer 2011; 11(4): 289-301.

[148] Alimonti A, Carracedo A, Clohessy JG, et al. Subtle variations in Pten dose determine cancer susceptibility. Nat Genet 2010; 42(5): 454-8. 
[149] Park KK, Liu K, Hu Y, Kanter JL, He Z. PTEN/mTOR and axon regeneration. Exp Neurol 2010; 223(1): 45-50.

[150] Zeng N, Yang K-T, Bayan J-A, et al. PTEN controls $\beta$-cell regeneration in aged mice by regulating cell cycle inhibitor p16ink4a. Aging Cell 2013; 12(6): 1000-11.

[151] Oviedo NJ, Pearson BJ, Levin M, Alvarado AS. Planarian PTEN homologs regulate stem cells and regeneration through TOR signaling. Disease Models \& Mechanisms 2008; 1(2-3): 131-43.

[152] Zhou D, Zhang $\mathrm{Y}, \mathrm{Wu} \mathrm{H}$, et al. Mst1 and Mst2 protein kinases restrain intestinal stem cell proliferation and colonic tumorigenesis by inhibition of Yes-associated protein (Yap) overabundance. Proceedings of the National Academy of Sciences 2011; 108(49): E1312-E20.

[153] Cai J, Zhang N, Zheng Y, de Wilde RF, Maitra A, Pan D. The Hippo signaling pathway restricts the oncogenic potential of an intestinal regeneration program. Genes \& Development 2010; 24(21): 23838.

[154] Demircan T, Berezikov E. The Hippo Pathway Regulates Stem Cells During Homeostasis and Regeneration of the Flatworm Macrostomum Lignano. Stem Cells and Development 2013; 22(15): 2174-85.

[155] Fraguas S, Barberan S, Cebria F. EGFR signaling regulates cell proliferation, differentiation and morphogenesis during planarian regeneration and homeostasis. Dev Biol 2011; 354(1): 87-101.

[156] Normanno N, De Luca A, Bianco C, et al. Epidermal growth factor receptor (EGFR) signaling in cancer. Gene 2006; 366(1): 2-16.

[157] Maemondo M, Inoue A, Kobayashi K, et al. Gefitinib or Chemotherapy for Non-Small-Cell Lung Cancer with Mutated EGFR. New England Journal of Medicine 2010; 362(25): 2380-8.

[158] Nautiyal J, Majumder P, Patel BB, Lee FY, Majumdar APN. Src inhibitor dasatinib inhibits growth of breast cancer cells by modulating EGFR signaling. Cancer Letters 2009; 283(2): 143-51.

[159] Jiang H, Grenley MO, Bravo M-J, Blumhagen RZ, Edgar BA. EGFR/Ras/MAPK Signaling Mediates Adult Midgut Epithelial Homeostasis and Regeneration in Drosophila. Cell Stem Cell 2011; 8(1): 84-95. [160] Seki E, Kondo Y, limuro Y, et al. Demonstration of cooperative contribution of MET- and EGFRmediated STAT3 phosphorylation to liver regeneration by exogenous suppressor of cytokine signalings. Journal of Hepatology 2008; 48(2): 237-45.

[161] Polakis P. Wnt signaling in cancer. Cold Spring Harb Perspect Biol 2012; 4(5).

[162] Nejak-Bowen KN, Monga SPS. Beta-catenin signaling, liver regeneration and hepatocellular cancer: Sorting the good from the bad. Semin Cancer Biol 2011; 21(1): 44-58.

[163] White BD, Chien AJ, Dawson DW. Dysregulation of Wnt/beta-catenin signaling in gastrointestinal cancers. Gastroenterology 2012; 142(2): 219-32.

[164] Laplante M, Sabatini DM. mTOR signaling in growth control and disease. Cell 2012; 149(2): 27493.

[165] May C, Sphyris N, Evans K, Werden S, Guo W, Mani S. Epithelial-mesenchymal transition and cancer stem cells: a dangerously dynamic duo in breast cancer progression. Breast Cancer Research 2011; 13(1): 202.

[166] Micalizzi D, Farabaugh S, Ford H. Epithelial-Mesenchymal Transition in Cancer: Parallels Between Normal Development and Tumor Progression. Journal of Mammary Gland Biology and Neoplasia 2010; 15(2): 117-34.

[167] Zhou B, Pu WT. Epicardial epithelial-to-mesenchymal transition in injured heart. Journal of Cellular and Molecular Medicine 2011; 15(12): 2781-3.

[168] Oviedo NJ, Levin M. smedinx-11 is a planarian stem cell gap junction gene required for regeneration and homeostasis. Development 2007; 134(17): 3121-31.

[169] Salameh A, Dhein S. Pharmacology of Gap junctions. New pharmacological targets for treatment of arrhythmia, seizure and cancer? Biochimica et Biophysica Acta (BBA) - Biomembranes 2005; 1719(12): 36-58.

[170] Mesnil M, Crespin S, Avanzo J-L, Zaidan-Dagli M-L. Defective gap junctional intercellular communication in the carcinogenic process. Biochimica et Biophysica Acta (BBA) - Biomembranes 2005; 1719(1-2): 125-45. 
[171] McLachlan E, Shao Q, Laird DW. Connexins and gap junctions in mammary gland development and breast cancer progression. Journal of Membrane Biology 2007; 218(1-3): 107-21.

[172] Adell T, Cebrià F, Saló E. Gradients in Planarian Regeneration and Homeostasis. Cold Spring Harb Perspect Biol 2010; 2(1).

[173] Nogi T, Levin M. Characterization of innexin gene expression and functional roles of gapjunctional communication in planarian regeneration. Developmental Biology 2005; 287(2): 314-35.

[174] Peiris TH, Hoyer KK, Oviedo NJ. Innate immune system and tissue regeneration in planarians: An area ripe for exploration. Semin Immunol 2014; 26(4): 295-302.

[175] Allen JE, Sutherland TE. Host protective roles of type 2 immunity: Parasite killing and tissue repair, flip sides of the same coin. Semin Immunol 2014; 26(4): 329-40.

[176] Godwin JW, Pinto AR, Rosenthal NA. Macrophages are required for adult salamander limb regeneration. Proc Natl Acad Sci U S A 2013; 110(23): 9415-20.

[177] Godwin JW, Rosenthal N. Scar-free wound healing and regeneration in amphibians: immunological influences on regenerative success. Differentiation 2014; 87(1-2): 66-75.

[178] Wenger $Y$, Buzgariu W, Reiter S, Galliot B. Injury-induced immune responses in Hydra. Semin Immunol 2014; 26(4): 277-94.

[179] Eming SA, Hammerschmidt M, Krieg T, Roers A. Interrelation of immunity and tissue repair or regeneration. Semin Cell Dev Biol 2009; 20(5): 517-27.

[180] Finkel T. Oxidant signals and oxidative stress. Curr Opin Cell Biol 2003; 15(2): 247-54.

[181] Glasauer A, Chandel NS. Targeting antioxidants for cancer therapy. Biochem Pharmacol 2014.

[182] Wondrak GT. Redox-Directed Cancer Therapeutics: Molecular Mechanisms and Opportunities. Antioxid Redox Signal 2009; 11(12): 3013-69.

[183] Sreevalsan S, Safe S. Reactive oxygen species and colorectal cancer. Curr Colorectal Cancer Rep 2013; 9(4): 350-7.

[184] Fruehauf JP, Meyskens FL. Reactive Oxygen Species: A Breath of Life or Death? Clinical Cancer Research 2007; 13(3): 789-94.

[185] Hagen H, Marzenell P, Jentzsch E, Wenz F, Veldwijk MR, Mokhir A. Aminoferrocene-Based Prodrugs Activated by Reactive Oxygen Species. J Med Chem 2012; 55(2): 924-34.

[186] Sinha B, Mason R. Biotransformation of Hydrazine Dervatives in the Mechanism of Toxicity. J Drug Metab Toxicol 2014; 5(168): 2.

[187] Weber JS, Samlowski WE, Gonzalez R, et al. A phase 1-2 study of imexon plus dacarbazine in patients with unresectable metastatic melanoma. Cancer 2010; 116(15): 3683-91.

[188] Nagai M, Vo NH, Shin Ogawa L, et al. The oncology drug elesclomol selectively transports copper to the mitochondria to induce oxidative stress in cancer cells. Free Radical Biology and Medicine 2012; 52(10): 2142-50.

[189] Xie C-M, Chan WY, Yu S, Zhao J, Cheng CHK. Bufalin induces autophagy-mediated cell death in human colon cancer cells through reactive oxygen species generation and JNK activation. Free Radical Biology and Medicine 2011; 51(7): 1365-75.

[190] Raj L, Ide T, Gurkar AU, et al. Selective killing of cancer cells by a small molecule targeting the stress response to ROS. Nature 2011; 475(7355): 231-4.

[191] Liu JM, Pan F, Li L, et al. Piperlongumine selectively kills glioblastoma multiforme cells via reactive oxygen species accumulation dependent JNK and p38 activation. Biochemical and Biophysical Research Communications 2013; 437(1): 87-93.

[192] Dhillon H, Chikara S, Reindl KM. Piperlongumine induces pancreatic cancer cell death by enhancing reactive oxygen species and DNA damage. Toxicology Reports 2014; 1(0): 309-18.

[193] Golovine KV, Makhov PB, Teper E, et al. Piperlongumine induces rapid depletion of the androgen receptor in human prostate cancer cells. The Prostate 2013; 73(1): 23-30.

[194] Jin H-O, Lee Y-H, Park J-A, et al. Piperlongumine induces cell death through ROS-mediated CHOP activation and potentiates TRAIL-induced cell death in breast cancer cells. Journal of Cancer Research and Clinical Oncology 2014: 1-8. 
[195] Yang F, Chen W-D, Deng R, et al. Hirsutanol A Induces Apoptosis and Autophagy via Reactive Oxygen Species Accumulation in Breast Cancer MCF-7 Cells. Journal of Pharmacological Sciences 2012; 119(3): 214-20.

[196] Yang F, Chen W-D, Deng R, et al. Hirsutanol A, a novel sesquiterpene compound from fungus Chondrostereum sp., induces apoptosis and inhibits tumor growth through mitochondrialindependent ROS production: Hirsutanol A inhibits tumor growth through ROS production. Journal of Translational Medicine 2013; 11(1): 32.

[197] Pierre A-S, Minville-Walz M, Fèvre C, et al. Trans-10, cis-12 conjugated linoleic acid induced cell death in human colon cancer cells through reactive oxygen species-mediated ER stress. Biochimica et Biophysica Acta (BBA) - Molecular and Cell Biology of Lipids 2013; 1831(4): 759-68.

[198] Bergamo P, Cocca E, Palumbo R, Gogliettino M, Rossi M, Palmieri G. RedOx Status, Proteasome and APEH: Insights into Anticancer Mechanisms of t10, c12-Conjugated Linoleic Acid Isomer on A375 Melanoma Cells. PloS one 2013; 8(11): e80900.

[199] Chen W, Feng L, Nie H, Zheng X. Andrographolide induces autophagic cell death in human liver cancer cells through cyclophilin D-mediated mitochondrial permeability transition pore. Carcinogenesis 2012; 33(11): 2190-8.

[200] Lim JCW, Chan TK, Ng DSW, Sagineedu SR, Stanslas J, Wong WSF. Andrographolide and its analogues: versatile bioactive molecules for combating inflammation and cancer. Clinical and Experimental Pharmacology and Physiology 2012; 39(3): 300-10.

[201] Yang S, Evens AM, Prachand S, et al. Mitochondrial-mediated apoptosis in lymphoma cells by the diterpenoid lactone andrographolide, the active component of Andrographis paniculata. Clin Cancer Res 2010; 16(19): 4755-68.

[202] Yu JQ, Bao W, Lei JC. Emodin regulates apoptotic pathway in human liver cancer cells. Phytother Res 2013; 27(2): 251-7.

[203] Wang W, Sun YP, Huang XZ, et al. Emodin enhances sensitivity of gallbladder cancer cells to platinum drugs via glutathion depletion and MRP1 downregulation. Biochem Pharmacol 2010; 79(8): 1134-40.

[204] Hou H, Li D, Cheng D, Li L, Liu Y, Zhou Y. Cellular Redox Status Regulates Emodin-Induced Radiosensitization of Nasopharyngeal Carcinoma Cells In Vitro and In Vivo. Journal of Pharmaceutics 2013; 2013(doi: 10.1016/j.bcp.2014.07.017.).

[205] Nishanth RP, Ramakrishna BS, Jyotsna RG, et al. C-Phycocyanin inhibits MDR1 through reactive oxygen species and cyclooxygenase-2 mediated pathways in human hepatocellular carcinoma cell line. European Journal of Pharmacology 2010; 649(1-3): 74-83.

[206] Nakata W, Hayakawa Y, Nakagawa H, et al. Anti-tumor activity of the proteasome inhibitor bortezomib in gastric cancer. Int J Oncol 2011; 39(6): 1529-36.

[207] Goel A, Aggarwal BB. Curcumin, the golden spice from Indian saffron, is a chemosensitizer and radiosensitizer for tumors and chemoprotector and radioprotector for normal organs. Nutrition and cancer 2010; 62(7): 919-30.

[208] Chatterjee SJ, Pandey S. Chemo-resistant melanoma sensitized by tamoxifen to low dose curcumin treatment through induction of apoptosis and autophagy. Cancer biology \& therapy 2011; 11(2): 216-28.

[209] Xu B, Guo X, Mathew S, et al. Triptolide simultaneously induces reactive oxygen species, inhibits NF-KB activity and sensitizes 5-fluorouracil in colorectal cancer cell lines. Cancer Lett 2010; 291(2): 2008.

[210] Salama S, Diaz-Arrastia C, Patel D, Botting S, Hatch S. 2-Methoxyestradiol, an Endogenous Estrogen Metabolite, Sensitizes Radioresistant MCF-7/FIR Breast Cancer Cells Through Multiple Mechanisms. International Journal of Radiation Oncology*Biology*Physics 2011; 80(1): 231-9.

[211] Wang W, Sun Y, Li X, et al. Emodin potentiates the anticancer effect of cisplatin on gallbladder cancer cells through the generation of reactive oxygen species and the inhibition of survivin expression. Oncol Rep 2011; 26(5): 1143-8.

[212] Hoshikawa H, Indo K, Mori T, Mori N. Enhancement of the radiation effects by D-allose in head and neck cancer cells. Cancer Lett 2011; 306(1): 60-6. 
[213] Yang ES, Choi MJ, Kim JH, Choi KS, Kwon TK. Withaferin A enhances radiation-induced apoptosis in Caki cells through induction of reactive oxygen species, Bcl-2 downregulation and Akt inhibition. Chemico-Biological Interactions 2011; 190(1): 9-15.

[214] Chun YJ, Park IC, Park MJ, et al. Enhancement of radiation response in human cervical cancer cells in vitro and in vivo by arsenic trioxide (As2O3). FEBS Lett 2002; 519(1-3): 195-200. overexpression of phospholipid hydroperoxide glutathione peroxidase. Hum Gene Ther 2006; 17(1): 105-16.

[216] Venkataraman S, Jiang X, Weydert C, et al. Manganese superoxide dismutase overexpression inhibits the growth of androgen-independent prostate cancer cells. Oncogene 2005; 24(1): 77-89.

[217] Goh J, Enns L, Fatemie S, et al. Mitochondrial targeted catalase suppresses invasive breast cancer in mice. BMC Cancer 2011; 11(1): 191.

[218] Hyoudou K, Nishikawa M, Kobayashi Y, Ikemura M, Yamashita F, Hashida M. SOD derivatives prevent metastatic tumor growth aggravated by tumor removal. Clin Exp Metastasis 2008; 25(5): 5316.

[219] Martín V, Herrera F, García-Santos G, Antolín I, Rodriguez-Blanco J, Rodriguez C. Signaling pathways involved in antioxidant control of glioma cell proliferation. Free Radical Biology and Medicine 2007; 42(11): 1715-22.

[220] Gianni D, Taulet N, Zhang H, et al. A Novel and Specific NADPH Oxidase-1 (Nox1) Small-Molecule Inhibitor Blocks the Formation of Functional Invadopodia in Human Colon Cancer Cells. ACS Chemical Biology 2010; 5(10): 981-93.

[221] Brar SS, Corbin Z, Kennedy TP, et al. NOX5 NAD(P)H oxidase regulates growth and apoptosis in DU 145 prostate cancer cells. Am J Physiol Cell Physiol 2003; 285: C353-C69.

[222] Mochizuki T, Furuta S, Mitsushita J, et al. Inhibition of NADPH oxidase 4 activates apoptosis via the AKT//apoptosis signal-regulating kinase 1 pathway in pancreatic cancer PANC-1 cells. Oncogene 2006; 25(26): 3699-707.

[223] Lemmo W. Potential interactions of prescription and over-the-counter medications having antioxidant capabilities with radiation and chemotherapy. Int J Cancer 2014: doi: 10.1002/ijc.29208

[224] VOLLBRACHT C, SCHNEIDER B, LEENDERT V, WEISS G, AUERBACH L, BEUTH J. Intravenous Vitamin C Administration Improves Quality of Life in Breast Cancer Patients during Chemo-/Radiotherapy and Aftercare: Results of a Retrospective, Multicentre, Epidemiological Cohort Study in Germany. In Vivo 2011; 25(6): 983-90.

[225] Fuchs-Tarlovsky V. Role of antioxidants in cancer therapy. Nutrition 2013; 29(1): 15-21.

[226] Li Y, Li X, Wong Y-S, et al. The reversal of cisplatin-induced nephrotoxicity by selenium nanoparticles functionalized with 11-mercapto-1-undecanol by inhibition of ROS-mediated apoptosis. Biomaterials 2011; 32(34): 9068-76.

[227] Sayin VI, Ibrahim MX, Larsson E, Nilsson JA, Lindahl P, Bergo MO. Antioxidants Accelerate Lung Cancer Progression in Mice. Sci Transl Med 2014; 6(221).

[228] Farnebo M, Bykov VJN, Wiman KG. The p53 tumor suppressor: A master regulator of diverse cellular processes and therapeutic target in cancer. Biochemical and Biophysical Research Communications 2010; 396(1): 85-9.

[229] Tovar C, Graves B, Packman K, et al. MDM2 Small-Molecule Antagonist RG7112 Activates p53 Signaling and Regresses Human Tumors in Preclinical Cancer Models. Cancer Research 2013; 73(8): 2587-97.

[230] Lu WJ, Lee NP, Kaul SC, et al. Mortalin-p53 interaction in cancer cells is stress dependent and constitutes a selective target for cancer therapy. Cell Death Differ 2011; 18(6): 1046-56.

[231] Chen F, Wang W, El-Deiry WS. Current strategies to target p53 in cancer. Biochemical Pharmacology 2010; 80(5): 724-30.

[232] D'Anneo A, Carlisi D, Lauricella M, et al. Parthenolide generates reactive oxygen species and autophagy in MDA-MB231 cells. A soluble parthenolide analogue inhibits tumour growth and metastasis in a xenograft model of breast cancer. Cell Death Dis 2013; 4: e891. 
[233] Xu Y, Fang F, Miriyala S, et al. KEAP1 Is a Redox Sensitive Target That Arbitrates the Opposing Radiosensitive Effects of Parthenolide in Normal and Cancer Cells. Cancer Research 2013; 73(14): 440617.

[234] Liu L, Chen C, Gong W, et al. Epoxyeicosatrienoic Acids Attenuate Reactive Oxygen Species Level, Mitochondrial Dysfunction, Caspase Activation, and Apoptosis in Carcinoma Cells Treated with Arsenic Trioxide. Journal of Pharmacology and Experimental Therapeutics 2011; 339(2): 451-63.

[235] Lu K-H, Lee H-J, Huang M-L, et al. Synergistic Apoptosis-Inducing Antileukemic Effects of Arsenic Trioxide and Mucuna macrocarpa Stem Extract in Human Leukemic Cells via a Reactive Oxygen SpeciesDependent Mechanism. Evid Based Complement Alternat Med 2012; 2012: 921430.

[236] Berndt C, Kurz T, Bannenberg S, Jacob R, Holmgren A, Brunk UT. Ascorbate and endocytosed Motexafin gadolinium induce lysosomal rupture. Cancer Letters 2011; 307(2): 119-23.

[237] Marengo B, De Ciucis C, Verzola D, et al. Mechanisms of BSO (L-buthionine-S,R-sulfoximine)induced cytotoxic effects in neuroblastoma. Free Radical Biology and Medicine 2008; 44(3): 474-82. [238] Syed Alwi S, Cavell B, Donlevy A, Packham G. Differential induction of apoptosis in human breast cancer cell lines by phenethyl isothiocyanate, a glutathione depleting agent. Cell Stress Chaperones 2012; 17(5): 529-38.

[239] Gupta P, Wright SE, Kim S-H, Srivastava SK. Phenethyl isothiocyanate: A comprehensive review of anti-cancer mechanisms. Biochimica et Biophysica Acta (BBA) - Reviews on Cancer 2014; 1846(2): 405-24.

[240] Klauser E, Gülden M, Maser E, Seibert S, Seibert H. Additivity, antagonism, and synergy in arsenic trioxide-induced growth inhibition of $\mathrm{C} 6$ glioma cells: Effects of genistein, quercetin and buthioninesulfoximine. Food Chem Toxicol 2014; 67: 212-21.

[241] Ong P-S, Chan S-Y, Ho PC. Differential augmentative effects of buthionine sulfoximine and ascorbic acid in As2O3-induced ovarian cancer cell death: Oxidative stress-independent anddependent cytotoxic potentiation. Int J Oncol 2011; 38(6): 1731-9.

[242] Wu X, Zhu Y, Yan H, et al. Isothiocyanates induce oxidative stress and suppress the metastasis potential of human non-small cell lung cancer cells. BMC Cancer 2010; 10(1): 269.

[243] Zhang L, Hao Q, Bao L, et al. Phenethyl isothiocyanate suppresses cervical carcinoma metastasis potential and its molecular mechanism. Molecular medicine reports 2014; 10(5): 2675-80.

[244] Tusskorn O, Prawan A, Senggunprai L, Kukongviriyapan U, Kukongviriyapan V. Phenethyl isothiocyanate induces apoptosis of cholangiocarcinoma cells through interruption of glutathione and mitochondrial pathway. Naunyn Schmiedeberg's Arch Pharmacol 2013; 386(11): 1009-16.

[245] Lee K, Briehl MM, Mazar AP, et al. The copper chelator ATN-224 induces peroxynitrite-dependent cell death in hematological malignancies. Free Radical Biology and Medicine 2013; 60: 157-67.

[246] Juarez JC, Manuia M, Burnett ME, et al. Superoxide dismutase 1 (SOD1) is essential for H2O2mediated oxidation and inactivation of phosphatases in growth factor signaling. Proc Natl Acad Sci U S A 2008; 105(20): 7147-52.

[247] Wu X-J, Kassie F, Mersch-Sundermann V. The role of reactive oxygen species (ROS) production on diallyl disulfide (DADS) induced apoptosis and cell cycle arrest in human A549 lung carcinoma cells. Mutat Res 2005; 579(1-2): 115-24.

[248] Yang JS, Chen GW, Hsia TC, et al. Diallyl disulfide induces apoptosis in human colon cancer cell line (COLO 205) through the induction of reactive oxygen species, endoplasmic reticulum stress, caspases casade and mitochondrial-dependent pathways. Food Chem Toxicol 2009; 47(1): 171-9.

[249] Kopetz S, Lesslie DP, Dallas NA, et al. Synergistic activity of the SRC family kinase inhibitor dasatinib and oxaliplatin in colon carcinoma cells is mediated by oxidative stress. Cancer Res 2009; 69(9): 3842-9.

[250] Kim H-S, Kim M-J, Kim EJ, Yang Y, Lee M-S, Lim J-S. Berberine-induced AMPK activation inhibits the metastatic potential of melanoma cells via reduction of ERK activity and COX-2 protein expression. Biochem Pharmacol 2012; 83(3): 385-94.

[251] Adhikary A, Mohanty S, Lahiry L, Hossain DMS, Chakraborty S, Das T. Theaflavins retard human breast cancer cell migration by inhibiting NF-KB via p53-ROS cross-talk. FEBS Letters 2010; 584(1): 714. 
[252] Lou J, Zhou X, Weng Q, et al. XQ2, a novel TPZ derivative, induced G2/M phase arrest and apoptosis under hypoxia in non-small cell lung cancer cells. Bioscience, biotechnology, and biochemistry 2010; 74(6): 1181-7.

1608 [253] Nishikawa M, Hashida M, Takakura Y. Catalase delivery for inhibiting ROS-mediated tissue injury and tumor metastasis. Advanced Drug Delivery Reviews 2009; 61(4): 319-26. [254] Hyoudou K, Nishikawa M, Ikemura $M$, et al. Prevention of pulmonary metastasis from subcutaneous tumors by binary system-based sustained delivery of catalase. Journal of Controlled Release 2009; 137(2): 110-5.

[255] Mirzayans R, Andrais B, Scott A, Murray D. New insights into p53 signaling and cancer cell response to DNA damage: implications for cancer therapy. J Biomed Biotechnol 2012; 2012: 170325. [256] Shen L, Sun X, Fu Z, Yang G, Li J, Yao L. The Fundamental Role of the p53 Pathway in Tumor Metabolism and Its Implication in Tumor Therapy. Clinical Cancer Research 2012; 18(6): 1561-7.

[257] Mirzayans R, Murray D. Pharmacological modulation of p53 function in cancer therapy. Curr Signal Transduct Ther 2008; 3(3): 183-94.

[258] Orlowski RZ, Baldwin AS, Jr. NF-kappaB as a therapeutic target in cancer. Trends Mol Med 2002; 8(8): 385-9.

[259] Sun B, Karin M. The therapeutic value of targeting inflammation in gastrointestinal cancers. Trends Pharmacol Sci 2014; 35(7): 349-57.

[260] Tornatore L, Sandomenico A, Raimondo D, et al. Cancer-Selective Targeting of the NF-kappaB Survival Pathway with GADD45beta/MKK7 Inhibitors. Cancer Cell 2014; 26(4): 495-508.

[261] Lin Y, Bai L, Chen W, Xu S. The NF-kappaB activation pathways, emerging molecular targets for cancer prevention and therapy. Expert Opin Ther Targets 2010; 14(1): 45-55.

[262] Yu X, Kensler T. Nrf2 as a target for cancer chemoprevention. Mutat Res 2005; 591(1-2): 93-102. [263] Jeong WS, Jun M, Kong AN. Nrf2: a potential molecular target for cancer chemoprevention by natural compounds. Antioxid Redox Signal 2006; 8(1-2): 99-106.

[264] Zhang B, Wang XQ, Chen HY, Liu BH. Involvement of the Nrf2 Pathway in the Regulation of Pterostilbene-Induced Apoptosis in HeLa Cells via ER Stress. J Pharmacol Sci 2014; 126(3): 216-29.

[265] Santarpia L, Lippman SM, El-Naggar AK. Targeting the MAPK-RAS-RAF signaling pathway in cancer therapy. Expert Opin Ther Targets 2012; 16(1): 103-19.

[266] Miller CR, Oliver KE, Farley JH. MEK1/2 inhibitors in the treatment of gynecologic malignancies. Gynecol Oncol 2014; 133(1): 128-37.

[267] Sebolt-Leopold JS, Herrera R. Targeting the mitogen-activated protein kinase cascade to treat cancer. Nat Rev Cancer 2004; 4(12): 937-47.

[268] Goldkorn T, Balaban N, Matsukuma K, et al. EGF-Receptor phosphorylation and signaling are targeted by $\mathrm{H} 2 \mathrm{O} 2$ redox stress. American journal of respiratory cell and molecular biology 1998; 19(5): 786-98.

[269] Roock WD, Vriendt VD, Normanno N, Ciardiello F, Tejpar S. KRAS, BRAF, PIK3CA, and PTEN mutations: implications for targeted therapies in metastatic colorectal cancer. The Lancet Oncology 2011; 12(6): 594-603.

[270] Baselga J. Why the Epidermal Growth Factor Receptor? The Rationale for Cancer Therapy. Oncologist 2002; 7(suppl 4): 2-8.

[271] Lui VW, Grandis JR. EGFR-mediated cell cycle regulation. Anticancer Res 2002; 22(1A): 1-11.

[272] Tan TC, Rahman R, Jaber-Hijazi F, et al. Telomere maintenance and telomerase activity are differentially regulated in asexual and sexual worms. Proc Natl Acad Sci U S A 2012; 109(11): 4209-14. [273] Ruden M, Puri N. Novel anticancer therapeutics targeting telomerase. Cancer Treat Rev 2013; 39(5): 444-56.

[274] Folini M. Editorial: targeting telomere maintenance mechanisms in cancer therapy. Curr Pharm Des 2014; 20(41): 6359-60.

[275] Crees Z, Girard J, Rios Z, et al. Oligonucleotides and G-quadruplex Stabilizers: Targeting Telomeres and Telomerase in Cancer Therapy. Curr Pharm Des 2014; 20(41): 6422-37.

[276] Lee P, Vousden KH, Cheung EC. TIGAR, TIGAR, burning bright. Cancer Metab 2014; 2(1): 1. 
[277] Rothwell PM, Fowkes FG, Belch JF, Ogawa H, Warlow CP, Meade TW. Effect of daily aspirin on long-term risk of death due to cancer: analysis of individual patient data from randomised trials. Lancet 1658 2011; 377(9759): 31-41.

1659 [278] Manda G. NMT, Neagu T.-M. Reactive Oxygen Species, Cancer and Anti-Cancer Therapies. Curr 1660 Chem Biol 2009; 3: 342-66.

1661 [279] Magnon C, Hall SJ, Lin J, et al. Autonomic nerve development contributes to prostate cancer progression. Science 2013; 341(6142): 1236361.

1663 [280] Barnett CM, Foote MC, Panizza B. Cutaneous head and neck malignancies with perineural spread to contralateral cranial nerves: an argument for extending postoperative radiotherapy volume. J Clin Oncol 2013; 31(18): e291-3.

[281] Liebig C, Ayala G, Wilks J, et al. Perineural invasion is an independent predictor of outcome in colorectal cancer. J Clin Oncol 2009; 27(31): 5131-7.

[282] Adriaenssens $E$, Vanhecke $E$, Saule $P$, et al. Nerve growth factor is a potential therapeutic target in breast cancer. Cancer Res 2008; 68(2): 346-51.

[283] Mescher AL, Neff AW. Regenerative capacity and the developing immune system. Adv Biochem Eng Biotechnol 2005; 93: 39-66.

[284] Yang SR, Rahman I, Trosko JE, Kang KS. Oxidative stress-induced biomarkers for stem cell-based chemical screening. Prev Med 2012; 54 Suppl: S42-9.

[285] Borovski T, De Sousa E Melo F, Vermeulen L, Medema JP. Cancer Stem Cell Niche: The Place to Be. Cancer Research 2011; 71(3): 634-9.

[286] Frank NY, Schatton T, Frank MH. The therapeutic promise of the cancer stem cell concept. The Journal of clinical investigation 2010; 120(1): 41-50.

[287] Xu Y, Stamenkovic I, Yu Q. CD44 Attenuates Activation of the Hippo Signaling Pathway and Is a Prime Therapeutic Target for Glioblastoma. Cancer Research 2010; 70(6): 2455-64. 